Portland State University

PDXScholar

1977

\title{
Self-Report of Illicit Adolescent Drug Use: a Methodological Discussion
}

\author{
Mario Bolivar \\ Portland State University \\ Judy Casey \\ Portland State University \\ Susan Goldsmith \\ Portland State University \\ Stanley Hahn \\ Portland State University
}

Follow this and additional works at: https://pdxscholar.library.pdx.edu/open_access_etds

Part of the Social Work Commons

Let us know how access to this document benefits you.

\section{Recommended Citation}

Bolivar, Mario; Casey, Judy; Goldsmith, Susan; and Hahn, Stanley, "Self-Report of Illicit Adolescent Drug Use: a Methodological Discussion" (1977). Dissertations and Theses. Paper 2054.

https://doi.org/10.15760/etd.2053

This Thesis is brought to you for free and open access. It has been accepted for inclusion in Dissertations and Theses by an authorized administrator of PDXScholar. Please contact us if we can make this document more accessible: pdxscholar@pdx.edu. 


\title{
SELF-RËPORT OF ILLICIT ADOLESCENT DRUG USE: \\ A METHODOLOGICAL DISCUSSION
}

\author{
by \\ MARIO BOLIVAR \\ JUDY CASEY \\ SUSAN GOLDSMITH \\ STANLEY HAHN \\ A praciticum submitted in partial fulfillment \\ of the requirements of the degree of
}

MASTER OF SOCIAL WORK

Portland State University

1977 
TO THE OFFICE OF GRADUATE STUDIES AND RESEARCH:

APPROVED BY:

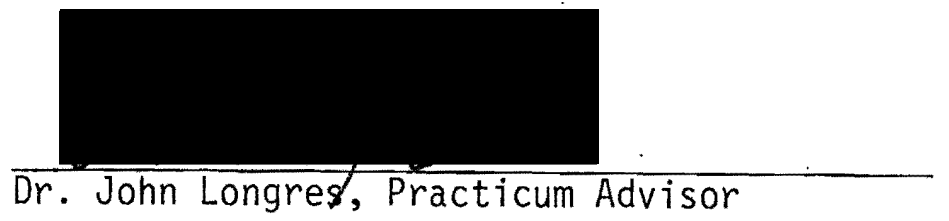




\section{ACKNOWLEDGMENTS}

The authors would like to acknowledge our husband, wives, children and friends who have stood by us with patience and kindness for the duration of the completion of this project.

We escepcially want to thank the various faculty members, adviors and field instructors whose support was with us when we needed it. Their guidance and encouragment was invaluable.

We also wish to acknowledge each other, throughout the process of completing this practicum we have all grown, and have learned some important lessons in giving and cooperating as a group. We thank each other for that. 
TABLE OF CONTENTS

ACKNOWLEDGMENTS

LIST OF TABLES

vi

LIST OF FIGURES

vij

CHAPTER

I INTRODUCTION 1

II REVIEW OF LITERATURE . 5

Official Statistics and Hidden Delinquency 5

The Robinson Study

The Witmer Study

The Schwartz Study

The Porterfield Study

The Short and Nye Study

The Provo Experiment

The Gold Study

The Hardt and Peterson Study

The Law Enforcement Assistance Administration Study

Drug Use in the Portland Area

The Oregon Journal Study

The Multnomah County Report

The Substance Abuse in Oregon Study

Summary of Portland Findings

II I METHODOLOGY

Dependent Variables: Criminal Activities in Drugs

Independent Variables

Sample

Instrument

Interviewing Procedure

Statistical Analysis

Interviewer Training

Limitations of the Methodology 41

Sample

Instrument

Interviewer Training

Final Word 
IV DISCUSSION 46

Bureacratic Complications $\quad 46$

Discussion of Events $\quad 50$

The School: Description and
History

Analysis of the Bureacratic
Complications

The Con Game 58

Loss of Involvement 59

Stalling $\quad 60$

The Sting 61

$\checkmark$ IMPLICATIONS FOR SOCIAL WORK PRACTICE 62

Role of Social Workers in
Public Schools

Expectations and Our Experience $\quad 65$

VI SUMMARY 68

$\begin{array}{ll}\text { APPENDIXS } & 70\end{array}$

A Original Idea for Dependent Variables
and Interviewing Schedules

B Colored Pictures of Three Different Types of Drugs. 111

C Hollingshead's Two Factor Index of

D Drug Use Seriousness ScaTe $\quad 114$

E Information Letter to Parents and

F Procedural Statment 121

$G$ Portland Public Schools, Job

Description of School

Social Worker

BIBLIOGRAPHY 


\section{CHAPTER I}

\section{INTRODUCTION}

In this paper we will discuss our unsuccessful attempt to conduct a self-report study of delinquent behavior in an urban multi-racial high school in Portland, Oregon. Much of this report reflects our preparation in conducting a self-report study and our analysis of why if failed.

In our research efforts we have found existing measures of adolescent misconduct to not differentiate clearly between juvenile delinquency and delinquent behavior. Juvenile delinquency is a label applied to young people as result of interaction with adults in position of authority: such as parents, the police, court workers, judges, social workers, psychologists, psychiatrists and lawyers. Results of these interactions usually appear in a number of quantifiable forms variously known as: delinquency rates, types and percentages of crimes committed by youth, sizes, of institutional populations delinquents and/ or persons in need of supervision, and caseload sizes. Delinquent behavior, in contrast, refers to illegal activities of behavior is, no doubt, more widespread a social problem than the detected reported delinquent behavior commonly referred to as juvenile delinquency.

The contention of this study is that delinquent behavior, and not juvenile delinquency is the major problem facing youth serving agencies and the public. The purpose of this study is an attempt to refine an often used method of measuring delinquent behavior - the self-report. Favoring a self-report: technique of data collection rather than an 
analysis of rate variations, a comparison of matched samples or a study of subcultures, tends to ground this study in a "radical non-intervention" approach to the field of delinquent behavior. (Schur, 1973) This particular approach views delinquent behavior as widespread throughout society rather than concentrated among the economically disadvantaged or in a certain subculture of the adolescent population. Also, contingencies are seen as operating in labeling behavior delinquent. One important contingency has been the differential treatment accorded youth by law enfiorcement agencies based on factors such as race, class, sex, age, grooming and demeanor. (Williams and Gold, 1972) Another contingency is the handling of cases of delinquent behavior by private social agencies, schools, churches and other more informal institutions. The results of more informal interactions may be left out of police and court statistics because of the presumed stigma of official labeling.

In this study we were initially concerned with the sociological concept of hidden delinquency. By the term "hidden delinquency" we mean delinquent behavior that is undetected by adults in position of authority.

Our original intent was to replicate part of Martin Gold's study Delinquent Behavior in an American City. (Gold, 1970) Gold used a selfreport methodology in the form of individual personal interviews with a sample of teenagers. He selected his sample from a general adolescent population and not from a sub-group of youth aiready officially labeled as "delinquent" or "deviant". Gold trained interviewers to question the teenagers in depth about specific lawbreaking acts the youth said they committed. The interviewers used an instrument, in the form of an 
interviewing schedule designed by Gold, to guide them in collecting data. The interviewers were young adults and were assigned to teenagers of the same race and sex. The interviews were conducted on "neutral grounds" such as in libraries and community recreation centers. Because Gold used a selfreport methodology, he did not know proportion of his sample would conceal offenses or whether rates of concealment would differ among teenagers of different socioeconomic status, race, sex, or age. The validation method Gold designed to study concealment will be discussed in the literature review.

We intended to study twelve dependent variables of delinquent behavior. They were vehicle theft, burglary, robbery, assault, trespass, fraud and con game, theft and shoplifting, property destruction, forcible rape, sale of $i 17 i c i t$ drugs, use of 117 icit drugs, and possession of $i 11-$ icit drugs. (see Appendix A) These variables were defined as lawbreaking acts performed by juveniles regardiess of whether or not they had been. brought to the attention of the authorities. We proceeded to operationalize the tweive variables and created a questionnaire for each of the acts. The original idea for a questionnaire and the operational definitions for each of the variables have been included in Appendix $A$. However, we realized that conducting a study using these large numbers of variables would be beyond the scope of this study. Part of the literature review is concernedi: with the official statistics and hidden delinquency which reflects on the twelve original variables that we wanted to study. As we developed our ideas we decided to focus only on conducting a self-report study of the use, sale, and possession of illegal drugs among adolescents in an. 
urban multi-racial Portland, Oregon high school. We wished to discover if the upward trend in drug use reported by Gold in this 1972 study of self-reported drug use is also evident in Portland. (Gold, 1975) Other reasons we chose to examine illicit adolescent drug use in Portland were because the national studies of illicit drug use that we examined excluded Portland from their sample. Another important rationale is that since marijuana possession and use has been decriminalized in Oregon our research study could possibly be the first step in determining whether or not there has been a rising trend in other drug use because of this.

We are directing our research efforts to social workers, psychologists, counselors, educators, and other youth serving professionals who are concerned or involved with the problems of juvenile delinquency and delinquent behavior. 


\section{CHAPTER II}

\section{REVIEW OF LITERATURE}

We have limited our presentation to the studies we believe have the most relevance and impact on the development of valid and reliable selfreport measures of delinquent behavior. For heuristic purposes we find i*: useful to categorize these studies into two general types:

1) Studies demonstrating the inadequacies of official statistics and highlighting the extent of hidden delinquency among the general adolescent population in various areas of the United States.

2) Studies of undetected or hidden illegal drug use behavior among adolescents in Portland, Oregon.

\section{A. OFFICIAL STATISTICS AND HIDDEN DELINQUENCY}

\section{The Robinson Study}

Robinson, in a ground breaking study of delinquent behavior in New York City in 1930 concluded that court figures alone are not only insufficient but also misleading as an indication of even the approximate extent of juvenile lawbreaking in New York City. (Robinson, 1936) She analyzed the data of official (court and police) as well as unofficial (schools and private social agencies) sectarian and non-sectarian, protective, preventive, and correctional agencies and institutions serving children exhibiting delinquent behavior. Her analyses revealed the following:

By Sex - The ration of boys to girls in unofficial court figures was $6 \frac{1}{2}$ to 1 . When other private or unofficial social agency data were 
added, this ratio decreased to 5 to 1 .

By Age - 01der children tended to appear in official data more often. Yet the extent to which this occurred was exaggerated if court and police data alone are used. Robinson found 1 child in 20 under 10 years of age referred to court for delinquent behavior. When unofficial data was added from schools and private social agencies the ration decreases ic: chitci in 12 .

By Race - Black children were represented in official delinquency statistics much more than would be expected on the basis of their proportion in the population. However, the dearth of black children in all but official agencies pointed to extreme differences in type of care avaitable for white and black children. Robinson concluded that any judgement as to the relative incidence of delinquency among black and white children would be very difficult to determine in light of this unbalanced situation.

By Religion - Where there was active organization of unofficial childcaring agencies, the incidence of officially registered delinquency was decidedly less. Thus, white - Prostestant and Jewish children were underrepresented as delinquents in proportion to the total child population, while black - Prostestant and Catholic children were overrepresented.

By Category - "children brought to court" - Robinson's analysis revealed differentials within and between neighborhoods as to peoples' atittudes towards the use of the court. Official data was seen as possibly lacking a considerable, yet varying proportion of serious offenses known only to schools and private social agencies. The variation was easily. 
seen by comparing children held for care by the court by area. For example, in Manhattan, for each child held for care by the court there was one child known to other agencies. The Queens, another borough of New York City, there were proportionately more children known to other agencies, than to the court. In Richmond, where there were no other agencies, the court figures presumably told all that was to be reported.

Robinson's work is a fine example of criticial, empirical, systematic social science research. It reveals some of the complexities and easily overlooked shortcomings of relying on official data for measuring the distribution of delinquent behavior.

The Witmer Study

Witmer et al, utilizing data from the now classic Cambridge-Somerville delinquency prevention project of the 1940 s, compared the delinquent behavior of two groups of delinquency prone youth - those known to the court and the project and those known only to the project. She found that court statistics are wholly inadequate as a measure of the amount of youthful illegal behavior from a collective as well as an individual point of view. As she clearly states:

In fact, so frequent are the misdeeds of youth that even a moderate amount of attention paid to it by law enforecement authorities could create the semblance of a "delinquency wave" without there being the slightest change in adolescent behavior. The same considerations throw doubt on the validity of court statistics as an index to change in amount of juvenile misconduct from time to time, for it is doubtful that such figures bear a consistent relationship to the unascertainable total. From the collective angle, then, court statistics appear as valuable to the administration of courts, but as not too useful to students of childrens behavior.

(Witmer, et a1. 1946, p.696)

Witmer also discussed how an adolscent's court record is a very inadequate measure of the amount of his or her anti-social conduct. 
Futhermore, the absence of a court appearance was seen as far from an indication that the youth was free from misconduct. Her study did show that on the average, official delinquents, somewhat more frequently committed serious offenses that unofficial delinquents, but there was much variation in even this aspect from case to case.

Once again we are reminded that official statistics are far from a complete account of $i l$ legal adolescent behavior. In this study an important political consideration of the delinquency issue is raised. If it is true that a moderate increases in the amount of attention paid to delinquent behavior is directed at certain income, ethnic, or religious groups in our society, then the impression may be generated that these particular groups are more deviant since their delinquency rate is higher than other groups who have not been paid a great attention. The manipulation of official statistics by newspapers and other media merit closer scrutiny if such are the consequences of official reports.

\section{The Schwartz Study}

Edward E Schwartz conducted a study through the period of 1943 to 1944 in the District of Columbia regarding community wide measurement of delinquency. The study had three primary objectives. They were: 1) to obtain comprehensive statistical data on the volume and nature of juvenile delinquency in the District of Columbia; 2) to test the differences between juvenile delinquency statistics obtained on a community wide basis with those obtained from the juvenile court alone; and 3) to explore the possible uses of registration data in the treatment and control of juvenile delinquency. (Schwartz 1945, p. 161) 
All the public agencies having responsibilities for dealing directly with delinquent children were included. Six public agencies participated. These agencies were: 1) The Juvenile Court; 2) Boy's Service Division; 3) Women's Bureau of the Police Department; 4) Public Welfare and Children's Services; 5) The receiving Home of the Board of Public Welfare and 6) The Department of Attendence and Work Permits of Board of Education; These agencies submitted to the Children's Bureau any child under 19 years of age who was referred because of alleged delinquency. Juvenile delinquency was defined as "any such juvenile misconduct as might be dealt under the 1aw". (Schwartz 1945, p. 159)

After one year of investigation, the results showed that juvenile court statistics are incomplete in a number of areas. The investigator found that juvenile court statistics not only included less than half of all the children registered for delinquency but aiso failed to include large numbers of children involved in types of delinquency considered serious, such as stealing, assault, and sex offenses. Another area included the proportions of boys and girls reported by the court for delinquent activities. In this, the court statistics showed considerably higher number of boys than were all the children registered in other agencies. Also the children reported by the court statistics were older than were ali the children registered. Schwartz concluded that The District of Columbia experimental registration serves to emphasize the importance of finding out, locality by locality, how satisfactory juvenile court statistics are as an indicator of juvenile delinquency, and to demonstrate how communities may obtain the information necessary to make this determination. (Schwartz 1945, p. 180) Schwartz's study serves of great importance 
in the study of delinquency. These findings affirm that juvenile court statistics alone are not an appropriate measure for determining who are the so-called "delinquents", what are the overall offenses committed by juveniles and when does a juvenile begin to commit offenses serious enough to need court intervention.

\section{The Porterfield Study}

Another important study that attempted to measure the extent of hidden delinquency was performed by Austin Porterfield. This study was conducted in Fort Worth, Texas in 1943. The investigator studied over 2000 cases of alleged delinquents in the Fort Worth area. Porterfield obtained characteristics and specific offenses for which children were brought to the juvenile court. He constructed a questionnaire listing the offenses for which a child would be brought to the juvenile court and administered this questionnaire to 337 College students. The questionnaire covered eleven different catergories of delinquent behavior. They listed as follows: 1) Acts of Public annoyance. 2) Violations of traffic laws. 3) Malicious mischief. 4) Encroaching. 5) Personal affronts and injuries. 6) Vagabondage. 7) Liquor violation. 8) Theft. 9) Dishonesty. 10) Sex offenses. 11) Other cases ie. abuse and murder. (Porterfield 1943,pp. 201-202) Each of these categories were broken down into more specific offense. From the data a statistical comparison was made of delinquent behavior of college students with those of children from the juvenile court. Porterfield found that all of the students reported that they had engaged in at least one of the deviant acts. He reported that the average number of offenses admitted by males was 17.6 and for females 4.6. (Porterfield 1943,p.206) 
Also his data showed that although the delinquent behavior of college students was as serious as those of children in court, there were few instances in which college students went to court for their offenses. Porterfield differentiated the outcome of the two groups terms of a) socioeconomionit: status of the family b) family disorganization c) the character of the complaint and nature of the complaint and d) neighborhood and community disorganization. He summarized his investigation by suggesting that children may be taken more often to court when committing a delinquent act because he or she comes from the "poor side of town". On the other hand, juveniles from high socioecomonic backgrounds do not come into contact with the juvenile court because they are either ignored by the police or processed informally. Finally, children from poor and desintergrating neighborhoods are prey to being closely watched by the police and thus have a higher probability of coming into contact with the juvenile court than juveniles from more affluently defined sections of the city.

The Porterfield study raises an interesting issue. Individuals involved in delinquent behavior, which becomes official statistics, have a definite set of interpretive characteristics defined and given by others. These interpretive processes are precipitated by a vast range of situational behaviors and tend to define the meaning of an individual's past and present behavior. The officially delinquent individual assumes a particular ascribed role. Because this role is a formal and functional component of the social system, there are powerful restraints that prevent the delinquent from ever abaridoning it. However, as we look at the Porterfield study, one can infer that if individuals commit acts that do not become official (hidden delinquency) those individuals do not assume the defined 
set of characteristics given by others. Officially designated delinquency formally authenticates a specific role individuals play in society. Hidden delinquency looks at a greater part and presents a more realistice picture.

\section{The Short and Nye Study}

During the 1950's there was much natioant concern with juvenile delinquency. This concern took various forms ranging from seemingly sopisticated scientific studies to sensationalistic newspaper headlining. Researchers trying to measure the effects of television and comic-book violence on children came before Congressional hearings. Perhaps this attention stemmed from the nation's expectation that the post World War II babyboom generation was emerging into adolescence. In any case, research concerning the inadequacies of court and officia'i statistics continued.

Throughout the 1950's James Short and Ivan Nye conducted a number of studies examining the extent of unrecorded delinquent behavior. They compared groups of midwestern and western male and female high school and college students to a state training school population. The authors found delinquent behavior among the high school and college population to be extensive and varied but not as frequent and serious as the delinquent behavior admitted to be the training school population as reported by their questionnaires. (Short \& Nye, 1958) The major shortcoming of Short and Nye's extensive research is that it was conducted almost exclusively in training schools or high schools by anonymous questionnaires. We consider these two agencies of socialization inappropriate settings for conducting research of as sensitive a nature as an adolescent's self-report of his/her 
delinquent behavior.

The Provo Experiment

In 1961, the Juvenile Delinquency and Youth Offenses Control Act was passed by Congress. I.t authorized the expenditure of $\$ 10$ million for grants to "youth development" projects for the prevention and treatment of juvenile delinquency. (Piven and Cloward, 1975) One such allocation went to the Provo Experiment in Delinquency Rehabilitation conducted in Utah under the Teadership of Maynard Erickson and Lamar Empey. Four groups of boys 15 to 17 years old were studied. Fifty high school "non-delinquent" boys, fifty who had appeard once in juvenile court, fifty juvenile reapeaters or persistent offenders, and fifty:incarcerated delinquents were interviewed by skilled interviewers probing their delinquent behavior. With respect to court records being inadequate measures of delinquent behavior, the authors found that nine times out of ten, most offenses went undetected and unacted upon. This was the case with respect to relatively minor violations such as traffic offenses, thefts of articles worth less than $\$ 50$, buying and drinking liquor and skipping school. For more serious offenses such as thefts of articles worth more than $\$ 50$, auto theft, breaking and entering, and forgery, fewer of these offenses went undetected. Yet even in these cases, eight out or ten reported that their violations went undetected and nine out of ten did not result in court action. (Empey and Erickson, 1963) Futhermore, the institutionalized boys' self-reported offenses were very much the same as the self-reported offenses of fifty juvenile persistent offenders living in the community. This finding suggests that where persistent offenders are involved, the decision to 
incarcerate may be highly subjective. Factors other than the extent and seriousness of these offenses seem to determine whether they are incarcerated or not. (Empey \& Erickson, 1963) Persistency rather than institutionalization seems to be the more important variable in distinguishing among "delinquent" adolescents.

These findings go further than Short \& Nye's in revealing the inadequacies and biases of court records. In fact, these findings challenge Short and Nye's who found that the institutionalized population's delinquent behavior was more serious. However, it must be pointed out that Erickson and Empey's fifty persistent offenders may not have been in the community if it were not for the Provo Experiment which, most likely, provided extra staff and services.

: The authors concluded that the great majority of all delinquent offenses remain undetected and unacted upon. As to the usefuiness of official records, the authors posed that court and police data can distinguish between at least some of those youngsters who have been heavily del inquent from those who have not. Also, the records reflect a tiny, but consistently accurate portion of all offenses. (Empey and Erickson, 1963)

\section{THE GOLD STUDY}

Continuing along these lines and beginning in 1961, Martin Gold and his associates at the University of Michigan conducted numerous self-report studies concerned with the seriousness and frequency of delinquent behavior in Flint, Michigan, a city of about 200,000 people. Additional research was also conducted with national samples. of youth designed to be representative of Americans 13 to 16 years old. The national studies were 
intended to gauge periodic changes or trends in the frequency, seriousness, and distribution of delinquent behavior in the United States. The implications of these surveys will be taken up further on in this paper.

Gold defined delinquent behavior as illegal acts as well as acts the teenagers knew were $i l$ legal when they committed them. In the Flint study, only three per cent of the delinquent acts committed by sampled teenagers were detected. Of the 2,490 delinquent acts reported by 433 of 522 respondents, only 47 teenagers and their 80 offenses made it into police records. Most likely, these were the more serious offenses. Yet analysis of the data revealed 47 cases of unlawful driving away of an automobile, 134 cases of property destruction, 45 cases of assault, and 21 cases of armed robbery only one of which resulted in apprehension. (Gold, 1970) These findings seem preposterous if the assumptions of public safety and a. law-abiding citizenry are made. Neverthless, the Gold studies appear to prc vide more methodological safeguards than previous self-report studies because of unique validation techniques and the careful conducting. of interviews to minimize interviewer and interviewee bias.

The important methodological contribution of the Gold studies lies in efforts taken to insure valid data as much as possible. Because Gold used a self-report methodology, he did not know what proportion of his sample would conceal offenses or whether rates of concealment would differ among teenagers of different socioeconomic status, race, sex or age. Therefore, he designed a validation method to study concealment. Gold was introduced to a group of teenagers who would be likely to have information about the delinquent behavior of other teenagers. He met these 
"potential informants" with the aid of teachers, youth workers and other interested adults. Sometimes, informants would introduce him to other informants. Gold stated "over 50 informants were contacted and fewer than 10 youngsters" declined to co-operate. (Gold 1970, p. 20) In their introductions, the youths were assured of Gold's trustworthiness as a social scientist.

Gold explained his study to this group and asked them to give him $<$ names of youths who had committed delinquent acts for which they had not been caught. Gold also asked for as much information as they could tell him about the acts: where and when the acts occurred; who had been robbed or cheated; what had been stolen or damaged; and other "identifying" data. No second hand testimony was accepted. He also asked them how they happened to have had this information.

Gold used the information supplied to him by the informants to construct a second group of 125 youngsters. This group was known as the "validators". Gold said they did not know that he already had information he considered reliable about their delinquent behavior.

Data on concealment came from comparing the responses of the 125 validating respondents to what the informants had already said they had done. Gold found three types of respondents: "truth tellers", "concealers" and "questionables". A "truth teller" was a youngster whose admissions corresponded to what the informant said they had done, or who admitted to a more recent or serious offense. A "concealer" was a respondent who did not admit to the offenses that had been reported by the informant, or to a more recent or serious offense. A "questionable" 
belonged in neither of the two categories because his story did not match exactly the information Gold already had. Gold was not certain, in such cases, how the difference in information arose.

Gold concluded that $72 \%$ of the teenagers admitted everything the informants stated, or they admitted to more recent or serious activities. Seventeen per cent (17\%) appeared to be concealing offenses, while the remaining $13 \%$ were questionable. The information Gold gathered suggested that "truth tellers" and "concealers" were equally distributed among sex, race, and socioeconomic groups. (Gold, 1970)

An interesting finding to emerge from the Gold studies was that while police records held only three per cent of admitted delinquent acts, parents were aware of only twenty-five per cent of their youngsters offenses as reported by the sampled teenagers.

The data was analyzed by social status. This variable referred to the prestige hierarchy of occupations in our society. In general, those occupations that earn higher incomes and require higher levels of education are more prestigious in the eyes of almost everyone and have been so regarded for many years. (Gold, 1970) While this phenomenon may have been characteristic of public attitudes during the 1960s when Gold was writing, we cannot assume those findings still hold true today in the mid1970s. Nevertheless, we accept Gold's discussion and interpretation of social status in the absence of more recent comprehensive assessment. Lower or higher status youngsters, then, referred to social status based upon the occupation of the chief breadwinner of the family. Gold found that lower-status boys; but not girls, engaged more frequently and 
seriously in delinquent behavior. However, he found that this relationship has been exaggerated for boys. Specifically, the official Flint figures, like figures from many other jurisdictions, set the ratio of lowerincome to middle-income delinquents at about eight to one. But the selfreport data showed that for every two middle-income boys among the $20 \%$ most delinquent boys, there are three lower-income boys. (Gold, 1970) Gold attributed this distortion in the official data to the relationship between frequency of delinquency and the chances of getting caught, which mathematically compounds small differences in frequency between lower and middle-income boys into larger probabilities of getting caught. (Gold, 1970) It also stemmed from the greater seriousness of the lower-income boys' delinquent behavior, as that behavior is judged by authorities. Judgments of seriousness help determine official dispositions of offenses and thus, records of delinquency as wel1. Since we - laymen and professionals - have relied so heavily on official data, this exaggerated relationship between delinquency and poverty, so long with us in so many different places, has shaped our images of delinquency.

Gold concluded that there is indeed some truth to the relationship between delinquency and poverty but it is a good deal smaller than is commonly believed, and a weak one upon which to rest a broad theory of del inquency.

Studies comparing police records and self-reported surveys received increasing attention during the 1960 s especially studies that dealt with frequency, seriousness or distribution of delinquent behavior among various socioeconomic groups. (Williams and Gold, 1972) 


\section{The Hardt and Peterson Study}

Robert H. Hardt and Sandra J. Peterson conducted a study comparing police records and a self-repored survey during the early to mid 1960s. (Hardt and Peterson, 1968) The main emphasis in this study was to look at delinquent activity among various socioeconomic groups. The study identified four cities of a middle atlantic state for purposes of comparison. One of the four sites was a predominantly low income black section. Two other sites were low income white and the last was a middle income section of the community characterized by its low delinquency and high school dropout rates.

The population consisted of seventh, eighth, and ninth graders, attending one parochial school and four public junior high schools. A questionnaire was administered to 813 students. Included were 191 students from the black low income group, 386 in the white low income area and 336 in the middle income section. These figures were comparitiviey close to police statistics of the above four areas.

The questionnaire included four different sets of items to measure. The items included were: 1) theft;2) fighting;3) wayward acts;and 4) vandalism. The investigator in this study were concerned with delinquency rates in different neighborhoods with regards to proportion and seriousness of involvement.

The findings indicated that the lower income areas had more serious types of delinquent activities occurring more of ten than other areas. Principally,they discovered that the lower black area had the highest percentage of both, frequency and seriousness. However, the investigators did 
not point out the proportion of self-reported delinquent behavior to the police statistics. In all of the items already mentioned there was a larger percentage of misbehavior reported by the middle income area than the overall police statistics showed. For example, the police statistics revealed that only nine per cent of 340 boys of the middle income district had records for delinquent activities. Self-reported vandalism by 336 students revealed $29 \%$ in the more serious involvement, with $30 \%$ less serious $7 y$, and $42 \%$ much less. Each of these figures is proportionately higher than the overall police statistics. Again, in the wayward acts $14 \%$ were included in serious acts and 30\% not as serious. If one were to sum up the seriousness and frequencies of delinquent activities of the self-report middle income group in all of the items listed, the total would add to $51 \%$ which is much higher than all of the percentages in all three neighborhoods shown by the police. For purposes of comparions, the other self-report neighborhoods showed even higher frequencies of delinquent activities than the police statistics. Obviously, the investigators were not interested in the total amount, in both areas of frequency and seriousness, of delinquent activities. Again, a.11 in all, police statistics do not reveal a total picture of delinquent activities in a given community.

\section{The Law Enforcement Assistance Administration Studies}

More recent data on undetected crime (and delinquent behavior) was released in a recent LEAA study. The LEAA found that more than two-thirds of the personal crimes committed against Portland, Oregon residents during a twelve month period in 1974-75 were never reported to the police. (Berger, 1977) In addition to the Portland data, federal researchers 
found that residents of thirteen major U. S. cities were reported fewer than half of the personal crimes against the. The LEAA basedeits findings on interviews with more than 21,000 persons in these thirteen cities during 1975. The LEAA estimated Portlanders reported to police only $31.3 \%$ of the actual incidents of personal crimes - rape, robbery, assault, and theft from persons. This was down from $33.8 \%$ in a similar study done in1971-72. The LEAA estimated that Portland residents told police about $42.6 \%$ of a 11 household crimes - burglary, larceny from homes, and vehicle theft during the $1974-75$ period which was a drop from $43.9 \%$ of these crimes reported to police in 1971-72. Also, the category of commercial crimes showed a statistically significant increases in 1974-75.

In summary, these data confirm that court statistics are inadequate measures of crime and delinquency. The collection of official data on delinquent behavior offers a biased view of the extent of the problem. Up to this point we have focused on hidden delinquency in general. We now want to examine the type of delinquent behavior that appears to be most pronounced in the Portland area.

\section{B. DRUG USE IN THE PORTLAND AREA}

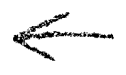

We chose to examine hidden illicit drug use because Gold found sharp increases in drug use for both sexes in a national study conducted under the auspices of the Institute for Social Research at the University of Michigan. In "Changing Patterns of Delinquency: 1967 - 1972", Gold reported changes were occuring in the delinquent behavior. (Gold, 1975) These changes were not in amounts of delinquent behavior but in style of delinquent behavior. Gold found that boys in 1972 reported less delinquent behavior than the 1967 sample but that the 1972 males reported more 
frequent use of illicit drugs, particularly marijuana. The 1972 male teenagers committed less frequent acts of gang fighting, trespassing, larceny, threatened assault, forcible and nonforcible entry, than did the 1967 males. In contrast, Gold found that while the 1972 females reported less larceny, breaking and entering, the property destruction than did the 1967 female sample, they showed a greater use of drugs, especially marijuana and alcochol. The use of drugs by females increased to such a degree in 1972, that even though other offenses declined, the 1972 female sample showed an increase in delinquent behavior. (Gold, 1975)

The Oregon Journal Study

The Oregon Journal printed a series of articles during the month of February of 1977 concerning the use of drugs among Portland high school students. These articles were based on actual experiences by a team of undercover reporters who visited Portland public high school grounds to learn about high school drug use and their availability.

The team of reporters, a man and a woman, worked undercover for a period of seven days in January of 1977 . There are a number of risks involved in working undercover. Thus the reporters attempted to be as unobstrusive as possible by posing as young people traveling around on a motorcycle, hustling drugs from high school students. The process was to drive to a high school and get to know 1) where the drugs were dealt or passed around, 2) to get to know the individuais with drugs and 3) to make a buy.

Their findings were astonishing. At all of the high schools that the undercover reporters visited, they found an abundant amount of drugs 
to buy. These drugs ranged from marijuana to amphetamines and LSD. They found these drugs not only relatively easy to obtain but also the transactions were done in the wide open, at everyone's visability. In fact, a school policeman reported that at a Washington County high school "they have a big area in the middle of the school where the students can sit and smoke it (marijuana) and the school ignores it." (Carman, et.al. 1977 , P. 3)

In summary, according to this report, high school drug use is intensive and extensive.

One of the major advantages of conducting this kind of natural environment research is that is allows the observation of illicit drug behavior without the restraints of stricter research designs. However, some limitations to this study are in order. Although the investigator reported an abundance of drugs among Portland high school students, amounts of drug use or frequency of drug use is not mentioned. What we do have is an editorial reporting, mostly from memory, which is far from collecting reliable data about illicit drug use. We do not know the ages of the high school population. In effect, some of the observed population may have been college students, young adults, or others who, like the investigators, may have been there at the proper time to obtain or sell drugs. Finally, there is an abundance of drugs as compared to what? Could it have been that this abundance of drugs has been there for years? Has illicit drug use and or drug sales increased since the decriminalization of marijuana in Oregon? If this is so, then the conclusion that there is an abuandance of illicit drugs in the Portland high schools may be grossly exaggerated 
or give a distorted impression. To determine àn accurate picture, carefully controlled information gathering is necessary if valid data are to result.

\section{The Multnomah County Report}

Reliance on official data to reveal trends in crime, delinquent behavior, mental illness, drug abuse, alcoholism and other "deviant" behavior may unnecessarily delay the implementation of ameliorative programs. Court data, as stated earilier, is often misleading and grossly inadequate with respect to the scope or extent of the problem.

The inadequacy in official statistics may have served as the basis for the Multnomah County, Oregon Division of Public Health undertaking a self-report survey of adolescent drug use in the Spring. of 1968. Referrals for drug offenses to the Multnomah County Juvenile Court ascended sharply from 1965 to 1968 (see Fig. I), but the actual extent of drug use by teenagers was disputed. In order to obtain evidence, the Multnomah. County Division of Public Health conducted a survey to define the extent of drug use among the high school age population as a basis for program planning by the Health Division and the community. Also, a more basic understanding of the distribution and dynamics of drug use among adolescents was sought. (Johnson, et. a1., 1971) For example, drug-to-drug correlations were planned as a step in resolving the dilemma of whether or not there is a progression from mild to hard drugs.

A questionnaire was adninistered to a random sample of 2,634 adolescents attending the public high schools of Portland and metropolitan Multnomah County, Oregon. The questions concerned use of marijuana, 
amphetamines, inhalants, sedatives and tranquilizers, cocaine, hal1ucinogens, narcotics, barbituates, alcohol, tobacco, headache remedies, cold remedies and antihistamines. Larger number of students were gathered together in assembly rooms or auditoriums for the purpose of data collection. Student questions were answered and reassurance was given that non-cooperation could be exercised in any manner the students chose. A quarantee of full anonymity was made. Deliberate attention was given to instructions and descriptions of slang terms related to each drug category.

Despite the impressive manner in which the data was presented there are important methodological weaknesses in this study. Essentially, we think the data is meaningless and see no point in presenting the findings. We will discuss the weaknesses of this study and the contribution it has made to our understanding of self-report studies of adolescent drug use. We consider the basic weakness of this study to be the manner in which the data were collected. Conducting a impersonal survey about behavior as personal. as consuming 111 icit drug is somewhat paradoxical. No amount of careful instructing and deliberate describing of directions can conpensate for the "mass-production-1ike" effect on conducting such a study in a large assembly hall or auditorium. It can be maintained that it was not rapport that was being south but undivided attention. Such as atmosphere is far from conducive to collecting reliable data about so sensitive a subject as consumption of illicit drugs. 


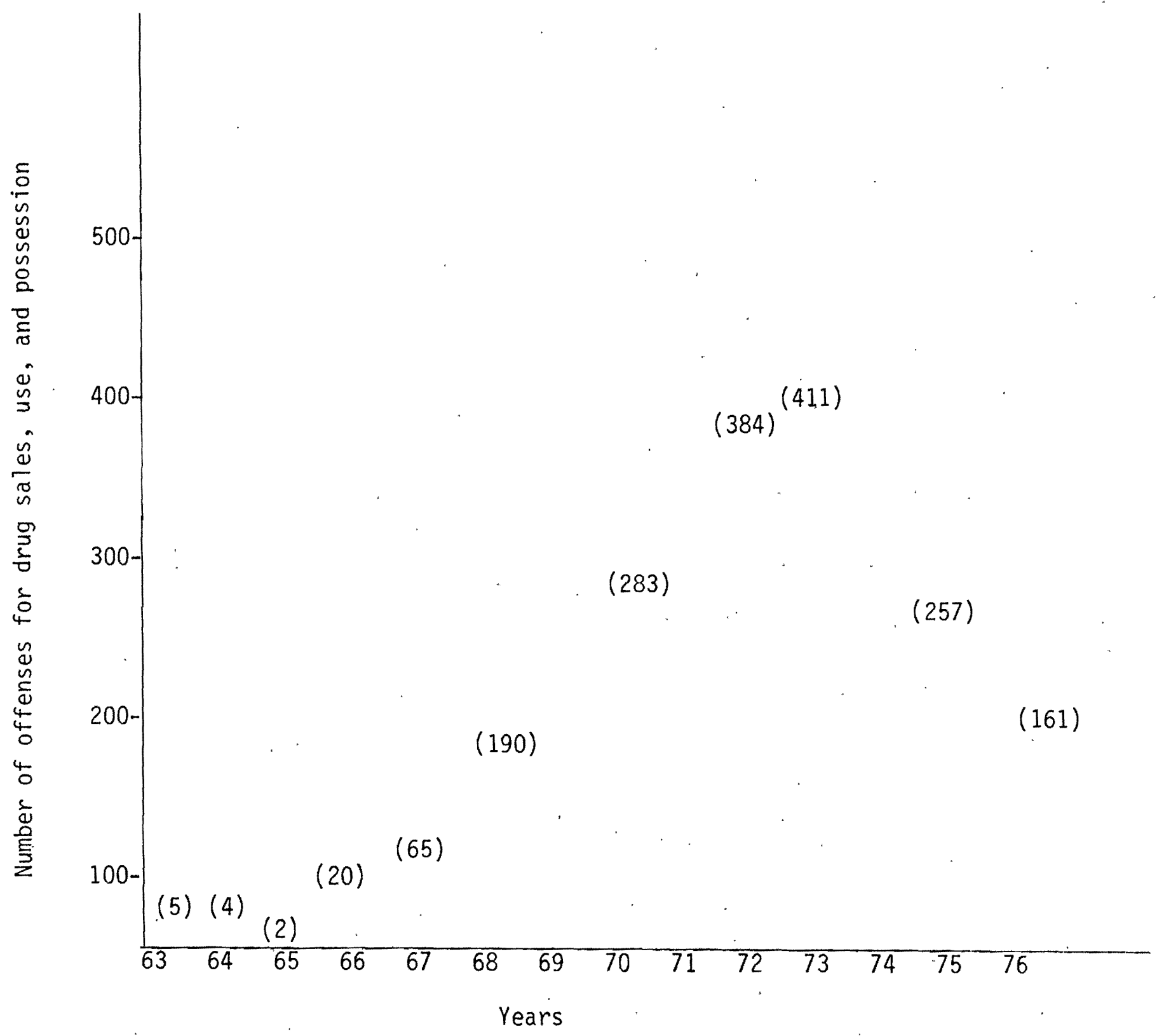

Figure 1. Drug related offenses per year: Portland, Oregon, Source: Multnomah County Juvenile Court Annual Reports, 1963-1968; 1971-1975. 
Secondly, comparison of self-reported drug use with social, psychological and environmental factors based on the responses of individual students was excluded from the design of this study. The researchers reasoned that trying to elicit this sort of information from the students would have increased their reluctance to reveal illicit practices. Instead, the authors compared self-reported drug use with 1960 Census data as reported in 1965 by the Portland City Planning Commission. The fundamental criticism we have about such a procedure is that social and economic characteristics of one population was compared with self-reported drug use behavior of another population eight years later.

Thirdly, a validation study was not reported by the authors. Therefore, it is not known how reliable this data gathering instrument was in eliciting accurate information on what is generally regarded as a sensitive subject. The above criticisms highlight the need for carefully controlled information gathering if valid data are to result.

In spite of the above criticisms we think this survey makes a contribution to the value of self-report drug use studies. It is in the development of a model for making valid correlations of associated drug use. Such information is important to those influencing social policy because it shows how strongly some drugs are used in association with others. The authors categorized the twelve drugs being studied into three levels of "popularity" as indicated by students in their questionnaires. The "least drugs used" category consisted of cocaine, halluciogens, narcotics and barbituates. The "intermediate used" drugs were marijuana, amphetamines, inhalants and sedatives and tranquilizers. The "most used drugs" 
included tobacco, alcohol, cold remedies and antihistamines, and headache remedies. More meaningful indices of reported drug use for the four most used drugs were developed.

...it was determined that levels other than rare or occasional reported use should provide the criterion for establishing a basis of correlation with reported use of the intermediate and least used drugs. Accordingly, the appropriate level for use of alcohol was set at 15 or more total times; daily use of tobacco was required; use for one or more times a year was set for cold remedies and antihistamines; use for eight or more times a year was the level chosen for headache remedies. (Johnson, et. a T. 1972, p. 167)

This correlation model, then, could define the relationships between any use of the least used drugs, any use of the intermediate used drugs and more than rare or occasional use of the most used drugs. Rare or occasional use of the most used drugs is considered to be the same as no use of these drugs. Table I depicts an interesting way of correlating reported use of amphetamines and marijuana with the reported use of other drugs based on the above categorization.

TABLE I

A MODEL OF CORRELATIONS OF ADOLESCENTS' REPORTED USE OF MARIJUANA AND AMPHETAMINES VERSUS OTHERS

Drugs

\begin{tabular}{|c|c|c|c|c|c|c|}
\hline Marij. & $\begin{array}{c}\text { Ampheta } \\
\text { mines }\end{array}$ & Total $\mathrm{N}$ & $\begin{array}{c}\text { Use } \\
\text { tobacco } \\
\text { daily }\end{array}$ & $\begin{array}{l}\text { lave used } \\
\text { alcohol } \\
16+ \\
\text { times }\end{array}$ & $\begin{array}{l}\text { Have used } \\
\text { any } \\
\text { narcotics }\end{array}$ & $\begin{array}{l}\text { Have used Have used } \\
\text { any any } \\
\text { barbs hallucinogens }\end{array}$ \\
\hline & & & & & & $N \frac{\%}{\%}$ \\
\hline
\end{tabular}

$\begin{array}{ll}\text { No } & \text { No } \\ \text { No } & \text { Yes } \\ \text { Yes } & \text { No } \\ \text { Yes } & \text { Yes }\end{array}$

Total

Source: Johnson, et. aT. "Survey of Adolescent Drug Use", American Journal of Public Health (June, 1972) p. 169. 
The Substance Abuse in Oregon Study

Part or our literature search consisted of contacting agencies in the city of Portland to discover if anyone was aware of self-report studies or measures of hidden adolescent drug use. The director and researcher of a State of Oregon Mental Health divison agency known as Constructive Options for Drug Abusers (CODA) informed us of a recently released study (November 1976) performed by Management Support Services of the Oregon Mental Health Division entitled Substance Abuse in Oregon: Ident. ifying Potential Clientele, Problem Trends and Service Related Needs. As its title states, this study as a definite treatment rather than assessment orientation. However, the methodology clearly asserts that conducting community surveys (e.g. self-report interviews):

... is thought to provide the most accurate and precise estimates of needs. However, aside from expense, such surveys are difficult to administer and while providing relatively more accurate estmates, may require a level of technical capacity beyond that which exists at most local levels. (Froland, $1976 \mathrm{p.}$ ) We grant that costs would be large. However, in a city the size of Portland, with several universities and colleges, there are probably persons with sufficient research expertise to handle the technical problems which could arise. In any case, a community survey of the type we have been advocating was not done. Given limited financial resources, this study utilized a research technique referred to as the "Synthetic Estimate Method." This strategy:

... is a similar but alternative approach to community survey methods. This method builds upon surveys already undertaken particularly those that demonstrate sufficient rigor and representative of the general population. Estimates of a local population's need are derived from the rates observed in such surveys for various segments of the population described in terms of their social and demographic characteristics. By adjusting the survey's rates to the unique composition of these characteristics in the local area, detailed approximations may be synthesized. (Froland, 1976 p. 17 )

Euphemistically, this technique may be considered an indirect way of measuring a problem that could be more accurately measured by direct 
means. Furthermore, not one person from Portland, Oregon was included in the national sample used in the study that was to serve as the basis for making synthetic estimates of substance abuse. This casts dorktit. on generalizing the findings of drug abuse to Portland's population. We urge an immediate assessment of drug use among the adolescent population utilizing a. self-report interview technique and administered to a representative sample of Portland teenagers.

\section{SUMMARY OF PORTLAND FINDINGS}

The data available for measuring the extent of drug use among the high school population in Portland, Oregon is inadequate. The studies that we reviewed and critically anaiyzed showed a number of methodological weaknesses. We conducted a search for reliable and valid data through a number. of agencies dealing with adolescents. These agencies reported being unaware of empirically sound studies relating to drug use. Many of the agencies directed us to CODA for information on reported and unreported drug use. 


\section{CHAPTER III}

\section{METHODOLOGY}

As stated previously, our original intent was to replicate part of Martin Gold's study, Delinquent Behavior in an American City. Gold used a self-report methodology in the form of individual interviews to question teenagers about specific law-breaking acts that the youths said they had committed. Gold id not know what proportion of his sample would conceal offenses or whether rates of concealment would differ among teenagers of different socioeconomic status, race, sex and age. Therefore, he designed a validation method to study concealment.

\section{Validation}

: Gold performed a validation study which compared the responses of 125 teenaged respondents to what informants had already said they had done. He found 3 types of respondents: "truth tellers", "concealers", and "questionables". Gold concluded that $72 \%$ of the teenagers were "truthtellers", that is, they admitted everything the informants had stated, or they admitted to more recent or serious activities. Seventeen percent $(17 \%)$ were "concealers" or appeared to be concealing offenses, while the remaining $13 \%$ were "questionables". "Questionables" were those whose stories did not match exactly the information revealed by the informants. The infor mation Gold gathered suggested that "truthtellers: and "concealers: were equally distributed among sex, race, and SES groups. (Gold 1970, p.21) In our study, we planned no validation study of our own. 
In the next section we will present the delinquent behaviors we chose to examine.

Dependent Variables: Criminal Activities in Drugs

Delinquent behavior, the dependent variable, was defined as drug related law-breaking acts performed by juveniles regardless of whether or not they had been brought to the attention of the authorities. The specific criminal activities in drugs we wanted to investigate and their definitions were:

1) Sale of illicit drugs; knowingly transfer or exchange drugs for money or other valuable goods or services.

2) Possession of illicit drugs: have on one's person or within one's control any drug prohibitied by statute or for which a person could be legally punished for having.

3) Use of illicit drugs: knovingly use or be under the influence of any narcotic or dangerous drug uniess the drug was dispensed or administered by a person authorized by law to do so.

Use of $i 11$ icit drugs would have investigated 3 categories of drugs: marijuana, amphetẽmines, inhalants, sedatives, cocaine, hallucinogens, narcotics and barbituates.

As an aid in identifying different drugs, the teenager would be shown colored pictures of the 3 classes of pills: amphetamines, barbituates and sedatives. (Appendix B)

We chose to examine these behaviors becasue the Multnomah Juvenile Court listed them as "delinquent" or law-breaking during the 19711975 period. Also, since comparison to court data would eventually be made it was important to have some basis for making comparisons. 
Independent Variables

Our independent variables were age, sex, race and socioeconomic status (SES). Age was defined as the number of years old the respondent was at the last birthday. Sex was defined as either male or female gender. Race was defined as White or non-White. Non-White included the following racial groups: Black; Native American; Mexican-American (Chicano); or 0ther. The determination of age and race was to be made by the respondents.

Socioeconomic status (SES) was to be measured by Hollingshead's Two Factor Index of Social Position in which the number of years of school completed and the occupation of the household head are scored on appropriate educational and occupational scales. (Appencix C) The scale value for education is multiplied by a weight of 4 and the scale value for occupation is multiplied by a weight of 7 . The sum of these two computations is assumed to be an index of the person's position in the class structure of his community. (Myers \& Bean, p. 16)

The scores on the Index range from 11 to 77 , with 11 representing the highest position an individual can reach in terms of education and occupation. A score of 77 would be assigned to a person with less than 7 years of schooling who was an unskilled laborer.

Myers and Bean in A Decade Later: A Followup of Social Class and Mental IIIness stated that the scores obtained on the Two Factor Index group themselves into 5 clusters and that each cluster can be assigned a single score to designate social class. The scores and class designation 
are as follows: (Myers and Bean p.237)

Range of Computed Scores

$11-17$

$18-27$

$28-43$

44-60

$61-71$
Social Class

I
II
IV
V

The highest prestige stratum is class I and the lowest class $V$.

We were uneasy about asking a youngster about his parent's job title or occupation because he simply might not know. However, we intended that careful interviewing would help us discover the answers to these questions. A cue to family income level was whether the youngster participated in the free or reduced price school lunch program. Eligibility for this program is based upon family size and income. Although we were not interested in income per se, the additional information provided by type of participation in the school lunch program might have aided us. Therefore, we planned to use it as a guideline or check in determining SES.

We chose the independent variables of age, sex, race and SES because previous studies of hidden delinquency have shown these variables to correlate highly with most others.

In the next section we will discuss the sample of youngsters we chose.

\section{Sample}

The students of a single high school in the city of Portland were to be the population from which we were to draw our sample. The school was chosen because of previous and current contacts we had there.

Within the school we drew a random sample of students, based on a 
computerized printout 1 ist of a 11 1,009 students enrolled during the 197576 school year. This list included the following data: student names; addresses; phone numbers; class year; race; and parent/guardian names. The procedure we used in selecting our random sample was to eliminate all special education students. Unilike most high schools, this particular one had a large program for youngsters with learning disabilities as well as blind and deaf students. We did not want to delve into the separate issues that would arise in studying delinquent behavior among this group. Graduating seniors were also excluded from our sample because they would not be attending school during the 1976-77 academic year when we would be conducting our interviews. Students enrolled in a half-day work/ school program were also excluded because their names would not appear on a school lunch program printout which was to be an aid to measuring SES. The population from which we drew our sample we thus reduced from 1,009 to 732 .

The next step was to draw the sample itself from the remaining 732 students. In order to insure that each student had an equal chance of being included in the sample, we numbered them consecutively on the printout and then consulted a table of random numbers to draw our sample of 160 students. We planned to interview 100 students and drew the back up sample of 60 in the event we could not contact designated students and in case of refusals to participate in the study. Gold found that $87 \%$ of those selected could actually be interviewed after 1osing $6 \%$ of the respondents through refusal and $7 \%$ through non-response. We anticipated a similar rate. Gold found the representativeness of his sample was not 
diminished by the failure to interview the missing 13\%. (GOLD p.10)

Our straight random sample of 160 students consisted of 85 males and 75 females; 45 of whom were 10th graders, 69 were 11 th graders, and 46 were 12 th graders in this school year. Non-Whites totailed $37 \%$, while Whites totalled $63 \%$ of the sample. In the entire high school population, Non-Whites totalled $32 \%$ and Whites totalled $65 \%$. In our sample then, NonWhites were slightly over-represented and Whites were slightly underrepresented.

Instrument

The instrument we designed for this study consisted of 3 parts: a check list defining the three criminal activities in drugs, an information sheet asking for age, sex, race, socioeconomic status (SES) variables, and type of participation in the school lunch program, and the schedules used for interviews.

The check list defined the three criminal activities in drugs: sale, possession and usage of 117 icit drugs, or dependent variables. Also, we intended that the definitions on the check list would tell the youngster what we meant by the terms drug sale, possession and use. The check list would be given to the respondent with the explanation that they were to check off the activities they had been involved in during this year.

The information sheet was a short form that asked the respondent's age, sex, race and type of participation in the school lunch program. It also asked the household head's occupation and number of years of education. The interviewer would carefully probe the responses to these SES variables. 
The schedule for the interview consisted of 3 different parts corresponding to the behaviors on the check 1ist; sale, possession and use of illicit drugs. The three parts of the schedule contained some standardized questions regarding frequency, "How often or many times have you engaged in (selling - using - poessing drugs)?"; length of involvement with activity, "How long have you been (selling - using - possessing drugs)?" ; motivation, "What are your reasons for (selling - using-possessing drugs)?"; and consequences, "Have you ever been caught?", "Who caught you?" and "What were the results of being caught?". Other questions in the schedule were not standardized because they related to a specific aspect of a criminal activity in drugs. For example, under "Selling Drugs", the respondent is asked "how much profit do you expect to make in a given week?" (See interview schedules $10,11,12$, Appendix A)

The questions on the schedule were almost all close ended. But, each question had an open-ended category designated as "Other" with space left for a write in answer. Questions regarding seriousness of a drug activity were left open ended. The schedules were to serve as guides to the interviewer and the respondent would not read or mark them.

We chose to use personal interviews because the data we wanted to gather was too complex and sensitive for a self-administered questionnaire. We wanted to know the who, what, where, when and how of the reported acts. Another practical consideration for having interviews, instead of questionnaires, was to control for students with reading difficulties.

The schedules used for interviewing then, were iritended to obtain a full description of each of the acts admitted to. These details would 
aid us in assessing the frequency and seriousness of each act.

The concepts of frequency and seriousness were part of the schedule design. Frequency ( $F$ index) referred to the total number of times the teenager reported the use, possession and sale of illicit drugs. While seriousness ( $\$$ index) referred to a score that was assigned by gathering information on the extent of reported physical injury to self when under the influence of drugs. (Appendix D)

The seriousness scores ranged from 1 to 4 . A score of 1 reflected the least amount of reported physical injury inflicted on self, for example, the respondent might have reported "slight difficulty in walking" or "slurred speech". A score of 4 reflected the maximum amount of reported physical damage infilictedri on self, such as, "Coma induced by drugs" or "attempted suicide" while on drugs.

The assessment of seriousness and frequency would allow us to assess the degree of teenager's drug use on a continuum, rather than separating youths into "drug users" and "non-drug users".

\section{Interviewing Procedure}

Gold contended that teenagers would be most likely to divulge their delinquent behavior to interviewers as close in appearance to their own age as possible, with the interviewers questioning youtbs: 6 f the same sex and race. Since our four person team consisted of no Non-Whites we would not always be able to match the interviewer with the same race student.

Each selected teenager and their parent/guardian were to be sent a letter. (Appendix E) informing them that they had been randomly selected 
to participate in a study examining teenagers' spare time activities. The letter urged cooperation, vowed confidentiality and informed the recipient that they would be telephoned to arrange a mutualiy convenient time for the interview.

Initially, the interview was to be held in a reserved room in the school building. Both parties were to be scheduled to meet at the appointed time for the interview. Upon further discussion, we decided not to use the school as an interviewing site because we assummed the students might not feel at ease reporting their drug behaviors in what they might perceive as an agency of social control. Instead, following Gold, we would conduct our interviews in community centers, libraries or fine stations. The interview would be initiated by the interviewer making a standardized statement about the intent and purpose of the study and how it was to be administered. (see appendix F) Included in this statement were further guarantees of protection from authorities and parental knowledge of disclosures. The respondent was to be assured that his/her name would not be put on any of the data sheets, and that a number would be assigned instead. The data obtained would only be used in group form, not individua11y.

At this point, the interviewer would ask the respondent to carefully consider the questions about to be asked and to answer them as honestly as possible. Once again, the respondent would be given a choice of participating or not with these considerations in mind. Indeed, it would be made clear that the respondent could withdraw from the interview at any point. 
If the respondent had decided not to continue, he would have been thanked for his time and honesty. We would have asked the respondent to keep our communications confidential to prevent contamination of our sample.

\section{Statistical Analysis:}

In this study we are concerned in measuring frequency, seriousness, and kinds of drugs used against the independent variables sex, age, SES, and race. A list of the drugs being studied here and the independent variables have already been mentioned earlier. We hoped then to proceed to test the following nul1 hypotheses:

$\mathrm{H}_{0_{1}}$ : There is no difference between seriousness and frequency of drug use among older and younger males and female high school students.

$H_{0}$ : There is no difference between seriousness and frequency of drug use

$\mathrm{O}_{2}$ among male and female high school students.

$\mathrm{H}_{\mathrm{O}_{3}}$ : There is no difference between seriousness and frequency of drug use among low to high degree of social status

$\mathrm{H}_{0}$ : There is no difference between seriousness and frequency of drug use $\mathrm{H}_{\mathrm{O}_{4}}$ among caucasian, black, mexican-american, oriental-american, and other high school students.

In addition to these, there will be a number of ad hoc hypothesis, not associated with the main hypothesis, to discover if there are any other relationships between groups.

To determine if there is a relationship between two or more drug variables, a cluster analysis can be used. For example, a cluster analysis can tell us if there is a correlation between reported use of marijuana and reported use of amphetamines.

A Multiple Regression can give us the degree of association between the frequency of drug use and the independent variables age, sex, SES, 
and race. Also, to test "between and within" race and drug use, an Analysis of Variance can be used. By means of an Analysis of Variance, we can test whether the variability between race and drug use is significantly greater than the variability within race and drug use at a given probability level. If we use the $5 \%$ probability level as the minimum for the determination of significance, this would indicate that the reported distribution of drug use in the different races would occur no more than five times in 100 . Again, the Analysis of Variance can be applied to the test "between and within" the other independent variables and drug use.

If funds were available to conduct this study with a much larger sample,a more appropriate test would be an Analysis of Variance with a Randomized Block design. This test would allow us to determine the interaction effects among the independent variable and drug use. However, this test would not be appropriate with a sample size of 100 . The cost in conducting this study with a much larger sample and using the Analysis of Variance with a Randomized Block Design is beyond our scope.

\section{Interviewer Training}

We intended to interview our sample of 100 , rather than train others to interview. We had designed our instrument and knew what specific data we wanted to gather. In preparation for the interviews, we took turns interviewing each other using our schedules. We role-played being teenagers and drew upon our own experience to answer questions.

\section{Limitations of the Methodology}

No research design is without limitations and ours were many. In 
this section we will critique our methodology.

Validation:

One of the major drawbacks of our design was that we excluded a validation check of our own. We know that this is a necessary part of a reliable study. However, we found it a difficult task and therefore planned to use Gold's $72 \%$ "truth tellers" as indicative of what we would have found in our sample.e. We now think this was a false assumption on our part. The limitations of Gold's validation method are several. First, Gold does not te11 us how many informants were used. He said "over 50 were contacted" and "fewer than 10" declined to cooperate. (Gold, 1970, p. 20) Second, neither the group of "informants" or "validators" were known to be a representative sample of youngsters from which to draw conclusions. Third, the validation method did not measure the problem of exaggeration. That is, to what extent do youngsters want to project daring and independent images? Gold's definition of a "truth teller" was a youngster who agreed with the informant, or "who admitted to a more serious or recent offense." If the youngster presented a more recent or serious offense; there was no validating evidence from the informant to deny or confirm it. Fourth, the use of informants did not supply information about delinquent acts committed by "loners". This group of teenagers were those that committed delinquent activities alone and did not discuss it with friends. However, Gold contended that a very small percentage of delinquent behavior is committed alone and that a still smaller percentage would keep their behavior secret from friends. With these drawbacks in mind, what validation technique might have been more reliable? 
In ariswer to this, we suggest two validation techniques, that when combined, reveal exaggeration and detect concealment. In the first method, names for non-existent drugs are invented by the researchers and interspersed among a list of existent drugs. Exaggeration is measured by the number of times the respondent admits to the use of a non-existent drug. In the second technique, a sample of youths would be randomly selected from drug clinic files. This group would be the "Index" group. The Index group would be matched for sex, age, SES, and race with a randomly selected group of teenagers from a high school population; the "Control" group. Our hypothes is is that the Index group, known users, should report higher rates of drug activity than the Control group, in a "double blind" interview. However, if the Control group reports more drug activity than the Index group then this would be a measure of concealment, or undetected drug use. (CODA 1976, pi:329) Both the Control and Index-groups would be given the list: with the nan-existent drugs included.

Sample:

Another weakness of our methodology was the smallness of our sample size. Our original sample of 100 was inadequate to test if the interactional effects among the independent variables of age, sex race and SES would be significant, using the Analysis of Variance with a randomized biock design.

An adequate sample size that would reveal significant differences among various groups using the above independent variables would be approximately 700 subjects. Since we drew our sample of 100 from a population of 732 , there wouldn't be a way to randomize the selection of 700 . Therefore, in order to keep our smaller size viable, we would need to limit our 
independent variables. However, this would have been unsatisfactory to us because we wouldn't have been able to study the key data we wanted. This is, what are the effects of age, race, and SES on juvenile criminal activities in drugs. Therefore, in order to include all the independent variables, we would now draw a sample of 700 from some centralized source of student data, such as a listing of all high school students in Area I.

Instrument:

The major limitation of our instrument was that we do not know how applicable it is to the measurement of adolescent criminal activity in drugs. This limitation arose primarily because we were never able to use it. Had we conducted a pre-test with a adolescent population, we could have "ironed out" some of the rough spots in our interviewing schedule. We know now a pre-test should have been run so that the instrument could have been refined.

Another part of our instrument, the seriousness scale, was designed by us and thus reflected our own biases in rating the seriousness of selfinflicted injury caused by drug use. To eliminate the bias, we could have asked a random sample of university students, teachers, doctors, drug treatment professionals, attorneys, home makers and others to rate the seriousness of the effects of drug use on selected adolescent cases. The responses would have then been placed in a ranking order to define the seriousness of the incidents. Although using the above sample of people would eliminate our biases, it still would involve the subjective judgement of others, albeit some with more expertise in such matters than others. 
Interviewer Training:

Our final.criticism of the methodology concerns the interviewer training. Ideally, we would have wanted to recruit interviewers more closely matched for age and race with our sample. The interviewers would have been selected from the undergraduate social work program at Portland State University. We would have trained them to use our instrument and helped them to refine their interviewing techniques. To control for interviewer effect on respondents, we would have asked our interviewers selected questions from our schedules relating to their use, sale and possession of drugs. Later, the results of the interviewer responses would be compared to those of the youngsters they interviewed. This would give us a check for interviewer effect, or the degree to which the interviewer bias influenced the type of behavior reported.

Final Word:

We have presented our criticisms of the methodology we used. However, we are aware that others will undoubtediy discover other limitations in the research design. We have proposed some changes that we think would improve our methodology, but we know that we have not exhausted the many possibilities avaitable. 


\section{CHAPTER IV}

\section{DISCUSSION}

Our research design was never implemented by us. Though the methodology had been completed and the sample was drawn, we had to terminate our study. We thought sanction for the study had been given to us by the appropriate people in the school system, but this proved to be untrue. A controversy concerning the sample and the means by which we had drawn it arose. We found that the school administrators were extremely exiusive in granting perinission to conduct our research. Their elusiveness was time consuming for us. We had to decide whether to proceed with our research using the sample they declared was illegally obtained, and risk reprisal from the school district and possibly the School of Social Work. Another choice was to collect a new sample in an alternative way and conduct the study as planned. The third, and finally selected choice, was to write a methodology paper detailing our methods, improvements upon them, and an analysis of the complications we experienced in working the Portland Public School District.

Bureaucratic Complications

This chapter will discuss the complications we encountered in attempting to receive permission to use the sarmple we had drawn. We will first outline chronologically, the significant meetings held with various officials in the school system. Following the chronology of meetings and events we will give a more subjective account of our feelings of being caught in a complex system whose rules and norms were unknown to us. This dilemma 
caused us to alter the course of research.

TABLE II

\section{CALENDAR OF EVENTS}

2-23-76 One of the research team members discussed the topic of self-report of delinquent behavior with his immediate supervisor. The supervisor gave the team member positive support and encouragement for a presentation of the idea to the vice-principal in charge of research and public relations at the high school.

2-29-76 The team member discussed the self-report study as an idea for a practicum project with the vice-principal in charge of research. He suggested a design for drawing the sample by grade level, sex socioeconomic status, race, and school achievement level.

3-2-76 The team member spoke to the acting principal about the feasibility of doing the practicum at his high school and left him a copy of the first procedural statement to explain the intent of the practicum.

3-8-76 The team member received a note from the acting principal saying, "Good. How are you going to set up the mechanics to get at 300 students? Discuss with the vice-principal in charge of research also." On the same day the acting principal was informed that the vice-principal had already been consulted by the team member and had given a favorable reaction to the proposition. The principal was asked if he would lend his support towards the practicum in writing so that when the permanent principal was selected, we would have some type of recommendation from the acting principal. The acting principal agreed to write such a statement and did so.

6-9-76 The practicum team met with the vice-principal in charge of research and public relations at the high school. The project was discussed with him and the team was introduced to the acting principal.

6-15-76 Two high school students were asked by a team member, to comment on whether or not they would want to participate in the study after being read the procedural statement about the nature and procedure of the interview. Both said they would participate if sampled. 
One student thought the statement was too repetitive and said it made him feel "dumb". The other student thought the statement was clear and respected the right it gave him to refuse to participate.

7-17-76 The team member obtained a copy of the high school's computerized print-out form of the students from the librarian with the permission of the acting principal. We drew our sample.

8-19-76 The team picked up the acting priricipal's memo saying that he supports the research project subject to: 1) a more detailed description of which subject areas we would examine and 2) how the research project meets with the approval of the vice-principals also. Another vice-principal looked for school policy pertaining to "outside" research projects, that is, projects conducted by researchers who are outside of the school system. She said that before she could allow such a study she would need an authorization from someone in the superintendent's office. This was the first mention of any involvement needed from anyone from outside the high school.

8-27-76 The team met with the District Head of Research at his office in a district elementary school to discuss the research project and to ask for an OK to proceed and start interviewing. He made copies of our procedural statement and the acting principal's letter. He advised us to contact the PTA and other parental groups to enlist their support. We told him that we had drawn our sample and were ready to contact parents of students selected. He said to keep the fact that we had already drawn our sample "under our hats". On this day, we also met with our practium advisor from Portland State University to discuss events so far.

10-29-76 The research team met with the District Head of Research and the Assistant Superintendent who is in charge of evaluation and research in the Area. The object of the meeting was to enlist his support which we considered to be very important because he was next in line in authority to the Superintendent. We discussed the nature and methodology of the study once again. The Assistant Superintendent had a copy of the entire interview schedule of the 14 areas we, at that point, wished to investigate. (We had submitted it earlier in the month.) He advised not to involve the PTA or community groups. He said he would contact the new principal of the school in regard to 
obtaining the school's okay. He also said he would send our interview schedule to the principal. We told him that we had already drawn our sample from the computer printout.

11-5-76 We met at the high school with the new permanent principal, two vice-principals and our practicum advisor from P. S. U. We discussed the nature of the study again for the benefit of the new people involved, and also discussed confidentiality, methodology, "the opportunistic nature" of "using" students to get our M. S, W. degrees. This subject was brought up by the woman vice-principal who had checked on school policy for outside researchers. She, apparently, was the head of outside research for the school. We also discussed at that meeting the sampling technique, variables, interviewing room, length of interviews, and whether or not the method by which we obtained our sample (by use of the computer listing) was permissable under school policy. The principal said he would contact the Districh Head of Research regarding the "Tegality" of our sample attainment. (Recall that the District Head already knew about our sample.)

The principal appeared concerned about "angry parents" calling with questions about the research project. He wanted to know if we would be available to answer calls from them. We agreed to do this.

One vice-principal stated that we would be dishonest if we didn't tell the parents in the letter we sent to them, the aspect of "spare-time" activities we were interested in.

We were offered the use of a school room to conduct our study in and we discussed interviewing the students during lunch hour.

11-9-76 A member of the research team spoke to the principal by telephone regarding the computer listing from which we had obtained our sample. The principal said the Head of Research did not know we had drawn our sample from the printout given to us by the vice-prinicpal. (This seemed strange because we had told him in detail how our sample had been drawn and from what source.)

The principal said the sample had been "illegally obtained" and that student's names and addresses could not be used by us according to school policy. 
We would be required to think of a new way to draw the sample before their approval could be given. The research team member said the approval process was taking too long, and since our time was limited we would pursue another side of the issue. The principal was thanked for his time, and was told we would not be in touch with the school again.

\section{Discussion of Events}

In reviewing the chronology of events, we believed that most of the feedback we were receiving from school administrators was positive until August 19, when the vice-principal informed us that we would need permission from the superintendent's office. That turn of events was a surprise to us since 6 months had passed since our first contacts were made with the school regarding the project. We had met with the high school administrators approximately 7 times previously, and no mention had been made of the necessity of involving the school board or superintendent. We had thought that we would be dealing solely with the high school administrators. Believing this, we had already obtained the listing of students, had drawn a sample, designed the instrument we intended to use, composed a letter to the parents describing our project and asking for their consent. (See Appendix J). We had set mid-September as our target date for starting our interviewing of students. In short, we had spent hours preparing the methodology, falsely thinking that with the school's consent alone we would have a clear path to begin our research. How optimistic and naive we were!

As the events listed in the calendar indicate, on August 27, we met with the District Head of Research. We were somewhat relieved when he gave us some support and positive feedback about our research plans. Since he was closely linked to the superintendent, we believed that having 
him "on our side" was vital to our plans.

We informed him of how we had obtained our sample and he told us to "keep it under our hats", implying that the acting-principal may have had no authority in allowing us to use the computer printout in collecting the sample or to collect it in another manner.

He encouraged us to seek support from the P. T. A. and other community organizations. He also told us that he would present our plans in "a positive light" to the area school board meeting. He made a copy of our introductory statement and took careful notes of our explanation of the experimental design for his upcoming presentation. We were asked to call him the next afternoon to find out the results of the meeting. When we did that, he reported that the board wanted to examine our interview schedules.

It took us two weeks to make the final draft of the interview schedule, which we mailed to him. At that time, we still interided to use the 12 dependent variables. For the next month, our communication with him was by telephone. Our project was in limbo at this point. We did not know whether we would be given approval to proceed. We were hestitant to begin mustering community support for fear that we would be rejected by the school board. We warited to be certain that the study existed before involving the community. This feeling of limbo continued for at least three weeks longer.

Our next meeting (10-29-76) was with the assistant superintendent and the District Head of Research.: They wanted to discuss our methodology in detail. The assistant superintendent had our interviewing schedule in hand and discussed it with us. He pointed out places where he thought 
revisions should be made, and seemed generally supportive of the study and its design. He also told us not to go into the community because it would interfere with our research progress by taking up too much of our time (which was becoming increasingly more limited). He wanted us to keep a low profile in the community and implied that he did not want our research to raise any "dust". This was a direct contradiction to the views of the District Head of Research, who had urged community involvement. We now felt not only in limbo about the future of our project, but also caught between two administrators in the school system with opposing points of view. We felt a dependency upon both for approval. They advised us to meet with the new principal for final approval and told us he would be given a copy of the schedule to examine. Our hopes were raised by the mention of a final approval.

The meeting (11-5-76) with the new principal included our research group, our Portland State University practicum adviser and two assistant principals. This was our first contact with the new principal which necessitated once again an explanation of our research goals and methods including where the interviews would be conducted and how students could be removed from class for participation in our study.

At this point, the question arose about how we had obtained our sample. We were told by one of the assistant principals that under school policy, it is not permissible to use the computer printout to obtain student information. The same person also informed us that she was the head of outside research for the school and she wondered why we had not contacted her. We were never told about her in all our contacts with other administrators. At this time, we were also informed that it is not usually 
allowable to conduct research unless employed by the school district. Since our project had begun when one of our team members had been working at the school, they felt that the project would probably be sanctioned, but that they would have to take the issue up at the board meeting. The principal said he would call the District Head of Research about our sample.

The principal, in a phone call a few days later, said he had spoken to the District Head about the sample. (Recall that he had told us to keep our sampling technique "under our hats".) The District Head denied any knowledge of how we had obtained our sample. This totally surprised us. As a result, we were told to obtain a new sample in an alternative manner. We were asked to return the original sample.

The date this occurred was November 9, and our target date for the beginning of the collection of data had been mid-September. Our time factor was so: 1 imited that we had no time to collect a new sample using another technique. It would have required a revamping of our methodology and that was something we chose not to do. We informed the principal of our decision, thanked him for his time and efforts, and said we would not be in contact with him again.

In the following sections we will analyze our lack of success in dealing with the public school system.

\section{The School: Description and History}

An analysis of our interactions with administrators of the Portland Public Schools is incomplete without a description of the historical forces that shaped the context within which we conducted ourselves.

The high school in which we operated was one of eighteen secondary schools for adolescents in the Portland public school district. 
At the time of our involvement, this school had been functioning for only eight years. The original educational model grew out of a doctoral dissertation by seven Harvard University education students. It was known as the School-Within-A-School Design. This model was based on the premise that education should be interdisciplinary, with all subjects wrapped together in a problem-solving approach. Students joined faculty in designing their own curricula and deciding what goals to reach for.

Team teaching was the original vehicle, with each student assigned to one of seven teams. Each team had 200 students, a leader, two experienced teachers and a number of trainees working toward teacher certification. Each team was responsible for its own administrative work, including budgeting and curriculum planning. Thus, a sense of real student involvement and participation in the learning process was a goal.

At the onset, the school received much acclaim. Charles Silberman, a nationally known and eminent educator once called the school, "The most comprehensive and systematic, and perhaps the most carefully thought-out attempt to create a new kind of secondary school." (Duncan 1976, p.1) Many visitors came to the school to observe this large scale attempt at experimental learning. Newsweek magazine featured comments by several noted educators.

Negative publicity was also present from the onset:

The opening of school was marked by racial confrontation. More bad publicity ensued when the student body refused the gift of an American flag from the Daughters of the American Revolution. (Maziotti 1975, p. 13) 
It appears that while there was much positive media publicity and fanfare, there was even greater community criticism which hit home more realistically. Within two months of the school's opening, a group of critical parents formed. Parents were concerned that their children were not being educated well enough to go to college. They were also questioning the apparent misconception that there was an atmosphere of excessive permissiveness between students and teachers.

The Harvard originators had departed by 1972, leaving behind an administration geared more to maintaining and clarifying public relations than committed to carrying on the polemics of meaningful contemporary educational methods and goals as well as instigating community support. Nevertheless, this administration maintained the original innovations in spite of the presence of more traditional minded middle-level administrators and a public attack by a Portland school board member. This attack alleged a lack of school discipline, vandalism and disruption. However, the highest ranking administrator of the entire public school system rallied to the defense of the school at the same time as he made recommendations for tightening up discipline, public accountability and the program evaluation procedure. It was his belief:

... that no administrative action be taken to change the central and important thrust of this important program. I strongly urge the Board of Education to reaffirm this at this meeting. No responsible school system in this nation, in my belief, can fail to investigate and explore needed improvements in high school education. (Duncan 1976, p. 8)

By 1976, the second principal had left, attendance and enrollment were down substantially, several junior-high feeder schools were eliminated, and cuts in faculty were projected. By the end of the school year, seven staff members were gone, two of the schools-within-a-school were 
eliminated and close to 300 students had been suspended for smoking cigarettes. (Colton 197.6, p.11)

The acting principal who presided over these changes was hired without consultation with the school staff or the community. Most of the faculty suspected the acting-principal of being hired as a "hatchet man" for one year. This charge was denied by the school board. Yet it proved to be an effective strategy for making cutbacks since the acting-principal would not be around to answer to the community the following year.

The acting-principal lended his support to our attempt to conduct the self-report study. In retrospect, we think the acting-principal misunderstood the underlying intent of our study. Most likely, he perceived our efforts to study delinquent behavior as lending support to his efforts to focus on how poorly the school was succeeding in preparing youth for responsible, law-abiding aduit roles. If we could have gathered our data, it could possibly have justified the acting-principal's actions involving making cutbacks in the educational program and among staff because much hidden delinquency would probably have been exposed, thus casting doubt on the school's original mission. From this perspective, our intentions to reveal the widespread nature of delinquent behavior with implications for continuning the development of meaningful alternative education models would be sabotaged.

In the next section we will present an analysis of the bureaucratic complications we encountered in our attempts to do reasearch in the school.

\section{Analys is of the Bureaucratic Complications}

Erving Goffman wrote an article entitled, "Cooling the Mark Out". 
We have found this article to be useful in understanding our situation with the school district. Goffman's framework of likening certain social interactions with a con game and the individuals involved in it seemed to fit fairly well for us. There are exceptions to the analogy, and we cannot explain all the events by using his ideas. We will include these exceptions within the description of Goffman's framework and how it can be applied to our experiences.

Although the school district neither refused nor gave us permission to do our study, they did make it difficult for us to continue. In essence, what they succeeded in doing can be termed "cooling the mark out."

Goffman, in his articie describes how in criminal fraud, or in confidence games, the victimes find their sources of security (often money) and status suddenly gone. The victims or prospective victims are termed "marks". They are the suckers, the people who are taken in. The con man, or "operator", wins the mark's confidence and gives him an opportunity to enter into some kind of fixed venture (i.e. gambling), and permits the mark to win and persuades him to invest more. Then an "accident" occurs, and the mark loses his entire investment. The operators collect, and then depart in a ceremony called the "blowoff" or "sting". (Goffman 1952,p.451)

Often, a mark is not prepared to view. his loss as a gain in experience arid may want to do something or "squawk" about it. He may want to go to the police, or pursue the operators. This is not good for the operators'business, so the cons may chose to employ an additional phase to avoid bad publicity. After the sting, an operator stays with the mark and attempts to maintain the mark's anger and console him in some kind of 
artful manner. In doing so, the "cooler" attempts to help the mark define the situation in a way that can be accepted and thus makes it easier for the mark to face the inevitable and go home quietly. The operator, or cooler, is in effect, giving the mark a lesson in the philosophy of taking a loss. This process, or phase is called "cooling the mark out". Goffman $1952, p .452)$

Goffman says that:

A consideration of this adaptation to loss can lead us to an understanding of some relations in our society between involvements and the selves that are involved. (Goffman 1952, p.452)

We think that htis is an appropriate way to view our experiences in working with the bureaucratic school system.

\section{The Con Game}

We think Goffman's frame of reference helps us understand the dynamics of the situation we found ourselves in with the public school system. Specificallt, we were involved in a congame: the school administrators were the "operators" and we were the "marks". We determined the school administrators to be the "operators" because we presumed they had more to lose than we did if potentially embarassing information about the performance of the school were to be revealed. This situation compelled the administrators into the role of operators although not of their own volition, but in response to the threat we were posing. We were the "marks" because we had less experience in working within the context of a larger public school system bureaucracy. Initially, in this game, we were permitted a small "win" when we received a memo from the acting principal stating his support for our study. The "accident" $r$ "mistake" occurred 
when the acting-principal gave us a computerized list of student data without "authorization" to do so. This turn of events caused us to lose our sample at a critical time. The "sting" occurred when we informed the principal that we had decided to pursue our research efforts along other lines. That is, we would not be conducting our research at the school. The operators collected by maintaining the school "status quo". We think this was their way of preserving a desired low profile in the community. We then lost our "involvement" (role, relationship, or status) within the school system.

\section{Loss of Involvement.}

Goffman describes three ways marks Tose their involvement: they can be promoted out of it; they can abdicate it; or they can be involuntarily deprived of their positions, and made something that is considered a lesser thing to be. (Goffman 1952, p.454)

This third description applies most directly to our experience: we were involuntarily deprived of our position and made to do something Tesser in return. We were forced because of time constraints to curtail our involvement and not to collect data as planned. We experienced feelings of loss and anger at this point.

A major exception to Goffman's framework at this point was the use of the third party. He does not mention them as part of a con game. Our practicum adviser, as a third party, provided us with an alternative or consolation prize. That prize was being allowed to do the study descriptively, rather than experimentally. Thus, this was the lesser project we chose; a methodological practicum. It was "lesser" in our minds because 
it was not what we had planned, it was a compromise. We did not want to discard all our work on the study.

\section{Stalling}

The other part of cooling us out was a tactic describec by Goffman as "stalling". The operators, school administrators, stalled by referring us to other administrators to seek approval. First, one of the vice-pribcipals said she wanted written approval from the Area Superintendent or his designate. After contacting the Superintendent's office, we were directed to consult with the District Head of Evaluation and Research. The District Head met with us and presented our proposai to an Area Board Meeting. The recommendation of the Board was that we meet with the Assistant Superintendent who told us that the ultimate decision rested with the school. This brought us full circle, back to where we began, but this timw there was a new principal at the school, who knew nothing about the project. As Goffman stated, in the stalling tactic:

The feelings of the mark are not brought. to a head because he is given not target at which to direct them. (Goffman 1952, p.453)

e became involved with so many operators in the system that we had no single person to hold responsible for what was happening to us.

Particularly appropriate to us, in Goffman's discussion of stalling, was the way the operators tried to convince us that there was still a slight chance that we could conduct the study or that the "loss would not occur". (Goffman 1952, p. 458) For example, instead of an outright refusal it was suggested that we find an alternative means of drawing our sample. Additionally, the school administrators, in a placating gesture, offered 
us a room in which to conduct interviews.

As Goffman described it:

When the mark is stalled, he is given a chance to become familiar with the new conception of self he will have to accept before he is absoluteily sure that he will have to accept it. (Goffman 1952, p. 458)

We came to know we would have to accept the lesser project and thus we were effectively cooled out. We also had to accept the view of ourselves as marks, rather than as shrewd people not about to be taken in by anything.

\section{The Sting}

In this analysis we have applied Goffman's conception of the "sting" to the school bureaucracy. We have described the "sting" as the "maintenance of the status quo" in the high school we wished to study. In our opinion, the school system maintains the status quo by perpetuating the conditions necessary for preserving its stability in the community.

Again, Goffman's framework is not entirely applicable to our experience because the school. administrators did not seek us out, as operators usually do. In our case, we sought them out. However, the end result was the same. As mentioned before, the acting-principal might have perceived our research plans as conveniently supporting his efforts to focus on how poorly the school was succeeding in producing "responsible, law-abiding" adults. Therefore, we became the marks and he an operator when he gave us his written support to conduct our research. The game continued, and changed with the cast of characters. The new principal seemed to want to maintain the status quo, and this meant cool us out. 


\section{CHAPTER V}

IMPLICATIONS FOR SOCIAL WORK PRACTICE

Our experiences with the public school system in Portland; Oregon have relevance for social work interns, practicioners, and other youthserving professionals interacting with public educational institutions. The school administrators' non-committal attitude and their effective method of shifting targets in order to avoid dealing with sensitive issues should direct change-agents to employ strategies designed to circumvent such behavior if progress towards social justice is to result. We now proceed with a discussion of the role of social workers in public schools and what they can do, as concerned professionals, about the problems of delinquent behavior and illicit adolescent drug use.

\section{Role of Social Workers in the Public Schools}

Social workers interact or intervene on behalf of individuals, groups, or populations coming into contact with or representing the school system and the community. Pincus and Minahan have suggested that social workers operate or conduct themselves within major postures or atmospheres of either collaboration, bargaining, or conflict. (Pincus and Minahan, 1973)

Collaborative relationships are characterized by a climate of trust, genuineness, and honesty between workers and people in need. There tends to be mutual agreement not only on what goals are sought, but on the methods for achieving them as well. Thus, a social worker who agrees to help a guidance counselor find alternative educational resources for a student 
who has stopped attending school is engaging in a collaborative relationship with the teacher and the willing student. In a situation where alternative educational resources do not exist, the worker may collaborate with other proffessionals and/or concerned people to develop such resources. Bargaining relationships involve testing the other party in order to determine what their goals are, what demand will be placed on all parties and what the outcomes of the change efforts might be. (Pincus and Minahan, 1973) The word "bargaining" implies that each party has something to gain as well as something to lose in the effort. A willingness to negotiate differences in desired goals and methods of obtaining them usually prevails. For example, a school social worker may be able to bring together representatives of the school, police, business community, and neighborhood residents in order to discuss and deal with the problem of vandalism in the community. A social worker may assist a group of high school students and faculty in trying to effect a change in policy so that permission for setting aside part of the school as a smoking area and lounge for students could be obtained.

...In some bargaining situations, the social worker is bringing parties together to enable them to bargain, and in others the social worker himself is in a bargining stance vis-a-vis another system. In the first case, the social worker may have collaborative relationships between himself and the individual bargainers and may be viewed by all concerned as a neutral, trustworthy mediator. In the second, the social worker is not neutral and may be seen as an advocate of a point of view trying to help a client system obtain something in the bargaining process. In the latter, case the social worker can be expected to use tactics of persuasion, negotiation, and even confrontation - and, occasionally guile - to enhance his bargaining position. (Pincus and Minahan 1973, p. 78)

Conflictual relationships arise when there is distrust between 
parties: Disagreement on means and ends may be so great that polarization occurs - the shared goals of the change agent and client systems appear to pose a serious threat to the self-interests of the target system and are perceived by the target as requiring major changes in its functioning. (Pincus and Minahan, 1973) Conflict is also likely to follow if there appears to be no desire to negotiate differences. A school social worker may enter into a conflictual relationship with parents who are unwilling to discuss blatant neglect or abuse of their children. The social worker may have to resort to legal sanctions in order to get the parents into a bargaining position. Once the parents are willing to negotiate and do so, a conflictual relationship no longer exists. A school social worker may advocate for a parents' group attempting to modify curriculum content by introducing a Black, Chicano, Puerto Rican, womens' or mens' studies program into the high school. If the school administrators perceive this action as a serious threat that may lead to undersired changes in basic status, power relationships, and control over resources, a conflict relationship can occur.

With all due respect to school social workers involved in advocating for progressive and meaningful changes in our public school system, we think that social workers normally maintain collaborative relationships with school administrators and faculty of the Portland Public Schools. Indeed, the position summary for the job description of a school social worker in the Portland Public School states:

School social workers work cooperatively with school staff, students, parents and community resource personnel in those areas of student behavior which interfere with the student's learning, social, and/or 
emotional adjustment. (See appendix $G$ for full description) In practice, we consider this policy usually results in the school being the client for the school social worker rather than the student population and their families. A policy of adjustment or adaptation to the school can be applied by the school social worker to problem situtations involving students, families, other agencies, and the school. Furthermore, we know of no position taken by school social workers in Portland, Oregon on such critical and urgent social issues as community participation in the control of schools, drug abuse, child neglect, busing, and youth unemployment. School social workers are most noticeable by their invisibility around such concerns. In order for school social workers to become involved and take an active part in addressing themselves to these issues they would probably have to engage in bargaining and perhaps even conflict relationships with schools administrations who want to keep a low profile in their communities. We think we attempted to engage the school administrators in a bargaining relationship which threw their expectations of us off base, and we were effectively cooled out over time.

\section{Expectations and Our Experience}

If social workers are expected to serve a primarily accomodating role in the public schools, then how did our request for permission to conduct self-report interviews around the sensitive area of delinquent behavior and drug use measure up to this?

One reason we like to cite for going on as long as we did was our skill in bargaining with school administrators. However, if we were so skillful, then why is it that our negotiating efforts did not bear fruit? 
We think the school perceived the possible outcome of our research to be not entirely in its self-interests. This is especially true for those who run the school and are held accountable for its performance. As far as two of the vice-principals are concerned, they would both be there to answer for possible negative findings from our study if it became public knowledge. Indeed, questions of confidentiality and privacy for students as well as anonymity for the school were raised repeatedly by these two vice-principals more than the other administrators. However, the acting principal and other vice-principal, both departing for academic posts elsewhere, and the new principal, did not have as great a stake in insuring the "stonewalling" of potentially negative information. They would have been either long gone or new at the job by the time the findings were made public, if they were made public at all. Therefore, they could have escaped being held accountable and were not as threatened as the other two viceprincipals. We wonder, in all this, if the two vice-principals were protecting their own vested interests in maintaining the status quo as much as the privacy and confidentiality of students and their families. Another implication for social work practice concerns our role as students working with a power structure like the public school system. It is insufficient to rely on conventional notions of where power to grant approval for request like ours actually rests. Inside knowledge of who may erect barriers, present complications, and devise stalling tactics needed to be obtained. Who are the possible sources of such information? One source might be "outside" researchers who have successfully negotiated with the school system and thus received approval of their research proposals. Independent organizational analysts with a firm grasp of the 
public school system's power structure are another source.

Finally, an implication for social work practice concerns our role as "clientless" bargainers. We really did not have the backing or endorsement of a group of parents or another group concerned with adolescent drug use and delinquent behavior. We think we would have carried greater "clout" in negotiations with the administrators if we had this kind of support. The school in question had two informal bodies of parent organization--the PTSA (Parents, Teachers, Students Association) and a number of parents organized around maintaining a federally funded "educationallydeprived" student program. They were known as the Title I Parent's Group. Together, these groups represented parents from various ethnic groups and income ranges. We think obtaining their support is necessary if research of a self-report nature with a representative sample of high school students is to be done. 


\section{Summary}

We have described in this paper our attempt to conduct a self-report study of delinquent behaviors. We contend that violations of the law invite a societal reaction which often exaggerates or gives a distorted impression of the significance of the behavior. A further contention states that norm violations however serious, do not distinguish clearly between the officially delinquent and the individual who remains undetected in the larger population. What actually leads individuals to be selected from a larger population with many potential "deviants" remains very problematic.

The above issues point out the importance of doing self-report studies to test the assumption that official statistics are an inaccurate measure of delinquent behavior.

Our original intent was to replicate part of Martin Gold's study, Delinquent Behavior in an American City. We intended to use a self-report methodology, in the form of individual personal interviews with a sample of teenagers. However, we were unable to use the sample we had collected and the shortage of time prevented us from collecting a new one. Therefore, we wrote a methodological paper instead. We have presented our proposed methodology and a critique of it, making recommendations for a more valid study.

We have presented an analysis of our interactions with the school system. The analysis made use of Goffman's framework of "Cooling the mark out." As a result of our efforts we maintain that conducting a self-report study of delinquent behavior within the school system is a complex task. We would be unjustified if we contended that the approach we have 
presented here is the only approach. However, we do contend that the framework presented here accounts for a much clearer picture of a delinquent behavior than the more narrow scope given by official statistics. 


\section{APPENDIX A}

ORIGINAL IDEA FOR DEPENDENT VARIABLES

AND

INTERVIEWING SECHEDULES 


\section{ORIGINAL IDEA FOR DEPENDENT VARIABLES}

1. Vehicle theft - take, operate, ride in another person's vehicle, boat or aircraft without the consent of the owner.

2. Burglary - entered or remained unlawfully in a building with the intent to commit a crime therein either with or without a dangerous weapon, or burglary tool, and/or with or without causing, threatening, or trying to physically injure someone.

3. Robbery - commit or intend to commit theft by using any of the following: a) physical force;b) represent by word or conduct that you have a dangerous/deadly weapon;c) atternpt to use a dangerous weapon; d) attempt or cause physical injury to any person in order to take property.

4. Assault - intentionally, knowingly, or recklessly cause physical injury to another by: a) criminal negligence-cause injury to another by use of a deadly weapon; b) cause serious physical injury by use of a deadly/dangerous weapon; c) cause death of another human being.

5. Tresspass - unlawful entry- enter or remain unlawfulity in or upon premises or dwelling.

6. Fraud, con game - Fraud is trying to get something (a right, benefit, or privilege) by lying about who you were, or how old you were. Con game is trying to get something by lying to a person about what you would do for him.

7. Theft, shoplift - taken, obtained or withheld property from the owner or taking property knowing it was the product of theft with a value of less than $\$ 200$ or taken a firearm or explosive.

8. Property destruction - intended to cause substantial inconvenience to a property owner or other person and as a result damage over $\$ 100$ worth of property; damage over $\$ 1000$ worth of property or accomplished damage by means oif an explosive.

9. Forcible rape - had sexual intercourse with a female 15 years or younger, or with a female that either was mentally incapacitated or physically helpless, or with a half-blooded sister, or a daughter.

10. Sale of illicit drugs - knowlingly transfer or exchange drugs for money or other valuable goods or services.

11. Possession of illicit drugs - have on one's person or within one's control any drug prohibited by statute or for which a person could be legally punished for having. 
12. Use of illicit drugs - knowlingly use or be under the influence of any narcotic or dangerous drug unless the drug was dispensed or administered by a person authorized by law to do so. 
Incident \# 1

Vehicle theft - take, operate, ride in another person's vehicle, boat or aircraft with the consent of the owner.

1. About how often have you done this?

a. once per week or more

b. once per month

c. 2 or 3 times per month

d. once or twice every four months

e. once or twice per year

2. Thinking of the last time you did this, what type of vehicle did you take?

a. motorcycle

b. car

c. van

d. truck

e. bus

f. other (specify)

3. Whose vehicle did you take?

a. parent/guardian

b. relative

c. friend

d. neighbor

e. other (specify)

4. Where did this happen?

a. within one mile of home

b. other part of city (more tha one mile from home)

c. another city or town

d. another state

5. Did you transport this vehicle across the state line? Yes No No

6. Were you with anyone? Yes No (If no go to question 7)

A. Who were they:

a. friend

b. relative

c. acquaintarice

d. stranger

e. other (specify)

$\begin{array}{ll}M & F \\ M & F \\ M & F \\ M & F \\ M & F\end{array}$


B. Did you take part or just watch?

a. took part

b. just watch

C. How many people were involved?

a. peers (number)

b. adults (number)

D. Whose idea was it to do this?

a. R's

b. everyone's agreement

c. other (specify)

7. Did you plan it? Yes_No____ (If No go to question 8)

A. How long did you plan it?

a. less than 5 minutes

b. 5 minutes to half-hour

c. more than 30 minutes

8. What did you do with the car?

a. R abandoned it

b. R stripped it

c. destroyed it

d. sold or traded it

e. returned it

f. other (specify)

9. What were your reasons for taking the vehicle?

a. anger

b. excitement

c. money

d. because my friends do it

e. revenge

10. When did this happen?

a. year

b. month

c. day

d. time AM

PM

11. Did you tel1 anyone about it later? Yes No (If No go to question 12)

A. How many people did you tell?

a. adults

b. peers 
B. What relationship were these people to you?

a. friend $M F$

b. relative $M F$

c. acquaintance $M F$

d. stranger $M F$

e. other (specify) M F

12. Were you caught? Yes_No___ (if No go to question 13)

A. By whom

a. police

b. owner of vehicle

c. stranger

d. other (specify)

B. What happened after you were caught?

a. jail

b. threatened

c. nothing

d. other (specify)

13. Did your parents find out about it? Yes No

A. How did they find out?

a. $R$ confessed

b. friends told

c. reported by police authorities

d. other (specify)

B. What did they do to you?

a. grounded

b. hit me

c. threatened

d. nothing

e. other (specify) 
Incident \# 2

Burglary - entered or remained unlawfully in a building with the intent to commit a crime therein either with or without a dangerous weapon, or burglary tool, and or with or without causing threatening, or trying to physically injure someone.

1. How often have you done this?

a. once per week or more

b. once a month

c. two or three times a month

d. once or twice every 4 months

e. once or twice a year

2. How did you enter the house or building?

a. force door or window

b. broke lock or glass

c. used explosives

d. other (specify)

3. Where was this?

a. in the neighborhood

b. other part of city

c. within 50 miles of home

d. over 50 miles of home

4. Were you with anyone? Yes

No

(If No go to question 5)

A. Who were they?

a. friends

b. relatives

c. acquaintances

d. stranger

e. other (specify) M

B. How many were there?

a. adults (numbers)

b. peers (numbers)

C. Did you take part or just watch?

a. took part

b. just watch 
D. Whose idea was it to do this?

a. R's

b. everyone's agreement

c. other (specify)

5. Was this activity planned? Yes_________ (If No go to question 6)

A. How long in advance?

a. less than 5 minutes

b. 5 minutes to half-hour

c. more than half-hour

6. What were your reasons for going into someone's property, building, or house?

a. angry at owner

b. curious

c. to have party

d. take something or get something

e. other (specify)

7. When did this happen?

a. Year

b. month

c. day

d. hour AM

PM

8. Did you tell anyone about it later Yes_No____ (If No go to question 9)

A. How many people did you tell?

a. adults

b. peers

B. What relationship were these people to you?

a. friends $M F$

b. relatives $M F$

c. acquaintance $M F$

d. stranger $M F$

e. other (specify) $\quad M{ }^{\prime} F$

9. Did anyone catch you? Yes_No_ No_ (If No go to question 10)
A. Who were they?
a. parent or guardian
b. authorities
c. passerby
d. owner
e. other (specify) 
B. How did they catch you?

a. owner told authorites

b. turned self in

c. parent told authorities

d. friends told

e. other (specify)

C. What happened to you after you were caught?

a. jailed

b. got a warning

c. sent to court or JDH

d. physically punished

e. nothing

f. other (specify)

10. Did your parents/guardians find out about it? Yes No

A. How did they find out?

a. from police

b. property owner told parents

c. friends

d. R confessed

e. other (specify)

B. What did your parents to or say?

a. yelled at me

b. placed me on restriction

c. physically punished me

d. gave me a calm warning not to do it again

e. nothing

f. other (specify) 
7. What were your reasons for doing this?

a. anger

b. for excitement

c. family hassles

d. other (specify)

8. Was it planned? Yes_No_ No_ (If No go to question 9)

A. How long in advance?

a. less than 5 minutes

b. 5 minutes to half-longer

c. one-half-hour to several hours

d. longer than several hours

9. Whose idea was it to do this?

a. respondent's

b. everyone's agreement

c. someone else's

d. other (specify)

10. When did this happen?

a. year

b. month

c. day

d. hour (specify) AM PM

11. Did you tell anyone about it later? Yes No

(if Yes)

A. How many people did you tel1?

a. adults

b. peers

B. What relationship are these people to you?

a. parent or guardian

b. teachers

c. brother or sister

d. friend (s)

e. stranger (s)

f. other (specify)

M F

$M F$

$M F$

M F

$M F$

M F

12. Did anyone catch you? Yes__No___ (If No go to question 13)

(if Yes)

A. How were your caught?

a. law enforcement authorities on patrol

b. stranger (passerby) reported incidnet

c. alarm went off 
Inčident \# 3

Robbery - commit or intend to commit theft by using any of the following: a) physical force; b) represent by word or conduct that you have a dangerous/ deadly weapon; c) attempt to use a darigerous weapon; d) attempt or cause physical injury to any person in order to take property.

1. How often did you do this?

a. once per week of more

b. once per month

c. 2 or 3 times per month

d. once or twice every 4 months

e. once or twice a year

f. not at all

2. What kind of weapon did you use?

a. knife

b. gun

c. chain

d. other (specify)

3. Did you use the weapon in this theft? Yes___No___ (If No go to question 5)

4. How bad was the injury?

a. no injury

b. bruised or cut

c. required professional care

d. required hospitalization

e. fatal

5. Where did this happen?

a. in your neighborhood

b. outside your neighborhood

c. outside city

d. outside state

6. Were you with anyone? Yes__No____ (If No go to question 7)

A. Who were they?

a. friend

b. relative

c. acqua intance

d. stranger

e. other (specify) 
d. turned self in

e. member of group confessed

f. victim told

g. other (specify)

B. What happened after you were caught?

a. court involvement

b. school discipline (specify)

c. other (specify)

13. Did your parents find out about it? Yes No Don't know

(if Yes)

A. How did your parents find out?

a. from neighbors

b. teachers

c. police

d. I told them

e. other (specify)

B. What did your parents do or say?

a. yelled at me

b. placed me on restriction

c. gave me a calm warning not to do it again

d. physically punished me

e. nothing

f. other (specify) 
Incident \# 4

Assault: intentionally, knowingly, or recklessiy cause physical injury to another by; a)criminal negligence-cause injury to another by use of a deadly weapon; b) casue serious physical injury by use of a deadly/dangerous weapon;

c) casue death of another human being.

1. About how of ten have you done this?

a. once a week or more

b. 2 or 3 times a month

c. once a month

d. 1 or 2 times every four months

e. 1 or 2 times a year

2. Thinking of the last time you did this, how bad was the injury?

a. no injury

b. bruised or cut

c. required professional care

d. required hospitalization

e. fatal

3. Again thinking of the last time you did this, who was the individual?

a. friend

b. parent

c. relative

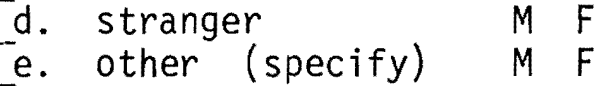

4. Did you use a weapon? Yes__ No___ (If No go to question 5)

A. What kind of weapon?

a. knife

b. gun

c. chain

d. rope

e. other (specify)

5. Where did it happen?

a. school

b. park

c. other (specify) 
6. About how far from your house?

a. $0-2$ blocks

b. 3-5 "

c. $6-10$

d. $11-20$ "

e. 1 mile or more

f. outside of neighborhood

7. Were you with anyone? Yes__No____ (If No go to question 8)

A. How many others were involved?

a. one

b. two

c. three or more

B. What relationship were they to you?

a. friends

b. relative

c. acquaintance

d. stranger

e. other (specify)

C. Did you actually take part or just watched?

a. took part

b. just watched

D. Whose idea was it?

a. $R^{\prime} s$

b. everyone's agreement

c. other (specify).

8. Did you plan it? Yes__ No____ (If No go to question 9)

A. How long did you plan it?

a. less than 5 months

b. 5 minutes to half-hour

c. more than half-hour

9. What was your reason for intentionally hurting an individual?

a. argument

b. did not lke him or her

c. revenge

d. fun

10. When did this happen?

a. year

b. month

c. day

d. time AM

PM 
11. Did you tell anyone about it later? Yes No...... (If No go to question 12)

A. How many people did you tell?

a. adults

b. peers

B. What relationship were these people to you?

a. friend

b. relative

c. acquaintance

d. stranger

12. Were you caught? Yes No (If No go to question 13)

A. By whom?

a. school authorities

b. police

c. stranger

d. other (specify)

B. What happened after you were caught?

a. jailed

b. threatened

c. nothing

d. other (specify)

13. Did your parents find out about it? Yes No (If No go to question 14)

A. How did they find out?

a. $R$ confessed

b. friends told

c. reported by school authorities or police

d. other (specify)

B. What did they do to you?

a. grounded

b. hit me

c. threatened

d. nothing

e. other (specify)

14. If the opportunity came along, would you intentionally hurt someone again?

a. yes

b. maybe

c. don't know

d. no 
Trespass -- unlawful entry- enter or remain unlawfully in or upon premises or dwelling.

1. How often have you done this?

a. once a week or more

b. once a month

c. two or three times a month

d. once or twice every 4 months

e. once or twice a year

2. How did you enter the house or building?

a. force door or window

b. broke lock or glass

c. used explosives

d. other (specify)

3. Where was this?

a. in the neighborhood

b. other part of city

c. within 50 miles of home

d. over 50 miles from home

4. Were you with anyone? Yes___No___ (If No go to question 5)

A. Who were they?

a. friends $M F$

b. relatives

c. acquaintances

d. stranger

e. other (specify) $M F$

B. How many were there?

a. adults

b. peers

c. Did you take part or just watch?

a. took part

b. just watched 
D. Whose idea was it to do this?

a. R's

b. everyone's agreement

c. other (specify)

5. Was this activity planned? Yes_No (If No go to question 6)

A. How long in advance?

a. less than 5 minutes

b. 5 minutes to half-hour

c. more than half-hour 6. What were your reasons for going into someone's property, building,
or house?

a. angry at owner

b. curious

c. to have a party

d. take something or get something

e. other (specify)

7. When did this happen?

a. Year

b. month

c. day

d. hour AM

PM

8. Did you tell anyone about it later? Yes No (If No go to question 9)

A. How many people did you tell?

a. adults

b. peers

B. What relationship were these people to you:

a. friends

b. relatives

c. acquaintance

d. stranger

e. other (specify) M F

9. Did anyone catch you? Yes_No____ (If No go to question 10)

A. Who were they?

a. parent or guardian

b. authorities

c. passerby

d. owner

e. other (specify) 
B. How did they catch you?

a. owner told authorities

b. turned self in

c. parent told authorities

d. friends told

e. other (specify)

c. What happened to you after you were caught?

a. jailed

b. got a warning

c. sent to court or JDH

d. physically punised

e. nothing

f. other (specify)

10. Did your parents/guardians find out about it? Yes No

A. How did they find out?

a. from police

b. property owner told parents

c. friends

d. R confessed

e. other (specify)

B. What did your parents do or say?

a. yelled at me

b. placed on restriction

c. physically punished me

d. gave me a calm warning not to do it again

e. nothing

f. other (specify) 
Incident \# 6

Fraud: tried to get something (a right, benefit, privilege) by lying about who you were or how old you were.

Con game: tried to get something by lying to a person about wint you would do for him.

1. About how often have you done tom

a. once a week or more

b. once a month

c. two or three times a month

d. once or twice every four months

e. once or twice a year

2. Thinking of the last time you did this, what fraudulent activity did you do?

a. used an alias

b. forged someone's signature

c. con game

d. used false ID - misrepresented your age as older or younger

e. claimed I was married

f. using someone else's credit card

g. other (specify)

3. Where was this?

a. at home (including on the telephone)

b. at school

c. in your neighborhood

d. outside your neighborhood

e. other (specify)

4. Who was the victim or intended victim of what you did?

a. friend

b. relative

c. acquaintance

d. stranger

e. other (specify)

5. Were you with anyone? Yes__ No___ (If No go to question 6)

(if Yes)

A. Who were they? 
$\begin{array}{ll}\text { a. } & \text { friend } \\ \text { b. } & \text { relative } \\ \text { c. } & \text { acquaintance } \\ \text { d. } & \text { stranger } \\ \text { e. } & \text { other (specify) }\end{array}$

B. Did you take part of just watch?

a. took part

b. just watched

6. Whose idea was it to do this?

a. respondent's

b. everyone's agreement

c. other (specify)

7. Was this activity planned? Yes No (If No go to question 8) (if Yes)

A. How long in advance?

a. less than five minutes

b. 5 minutes to one-half hour

c. longer that one-half hour

8. For what reason or reasons did you do what you did?

a. exciternent

b. money

c. revenge

d. reputation

e. other (specify)

9. What did you do with what you got?

a. used it (spent it)

b. gave it to paryt not involved

c. destroyed it or discarded it

d. another involved party used it

e. sold or traded it

f. don't know or other (specify)

10. When did this happen?

a. year

b. day

c. hour (specify)

d. month AM PM

11. Did you tell anyone about it later? Yes No (If No go to question 12) 
(if Yes)

A. How many poeple did you tell?

a. adults

b. peers

B. What relationship are these people to you?

a. parents

b. teachers

c. brother or sister

d. friend (s)

e. stranger (s)

f. other (specify)

$M F$

M F

$M F$

M F

$M F$

M F

12. Did anyone catch you or turn you in? Yes No (If No go to question 15)

\section{(if Yes)}

A. Who caught you or turned you in?

a. friend

b. relative

c. victim told

d. teacher

e. neighbor

f. law enforcement official

g. stranger

h. other (specify)

13. "How were you caught?

a. saw through my argument

b. by learning from someone else

c. other (specify)

14. What happened after you were caught?

a. got a warning

b. school discipline (specify)

c. placed on restriction

d. got beaten up or hit

e. got yelled at

f. sent to court

g. other (specify)

15. Did your parents or guardian find out about it? Yes No Don't know

(if Yes)

A. How did they find out?

a. from neighbors

b. teachers

c. friends

d. police 
e. victim

f. I told them

g. other (specify)

B. What did your parents do or say?

a. yelled at me

b. placed me on restriction

c. given a calm warning not to do it again

d. nothing

e. other (specify_) 
Incident \# 7

Theft: shoplift-taken, obtained or withheld property from the owner or taking proberty knowing it was the prodcuts of theft with a value of less than $\$ 200$ or taken a firearm or explosive.

1. About how often have you done this?

a. once a week or more

b. once a month

c. two or three times a month

d. once or twice every four months

e. once or twice a year

2. What did you take?

(open ended question)

3. Where did the incident take place?

a. home or residence

b. business or store

c. someone's car

d. school

e. other (specify)

4. 'About how far from your home did the incidnet take place?

$\begin{array}{lll}\text { a. } & 0-2 & \text { blocks } \\ \text { b. } & 3-5 & \text { " } \\ \text { c. } & 6-10 \quad " \\ \text { d. } & 11-20 \quad " \\ \text { e. } & 21 \text { or more blocks } \\ \text { f. } & 1 \text { mile or more }\end{array}$

5. How much was the item worth?

a. \$1-50

b. $\$ 51-200$

c. $\$ 201-500$

d. \$501-1000

e. more than $\$ 1000$

6. Did you use a weapon? Yes_No_No_. (If No go to question 7)

A. What kind of weapon did you use?

a. knife

b. crow bar

c. gun

d. other (specify) 
7. Were you with anyone? Yes_No____ (If No go to question 8)

(If Yes)

A. How many were involved?

a. one

b. two

c. three or more

B. Who were they?

a. friend

b. relative

c. acquaintance

d. stranger

e. other (specify)

C. Did you take part or just watched?

a. took part

b. just watched

D. Whose idea was it?

a. R's

b. everyone's agreement

c. other (specify)

3. Did you plan it? Yes_. No____ (If No go to question 9)

A. How long did you plan it?

a. less than 5 minutes

b. 5 minutes to half-hour

c. longer than half-hour

9. What was your reason for taking something not belonging to you?

a. excitement

b. family hassles

c. revenge

d. other (specify)

10. When did it happen?

a. year

b. month

c. day

d. time (specify) AM

PM

11. Did you tell anyone about it later? Yes No (If No go to question 12)

A. How many people did you tell?

a. adults

b. peers 
B. What relationship were they to you?

$\begin{array}{lll}\text { a. friend } & M & F \\ \text { b. relative } & M & F \\ \text { c. acquaintance } & M & F \\ \text { d. stranger } & M & F \\ \text { e. other (specify) } & M & F\end{array}$

12. What did you do with the item taken?

a. used it

b. returned

c. destroyed or got rid of it

d. sold or traded

e. another involved party used it

f. don't know

g. other (specify)

13. Were you caught? Yes___No___ (If No go to question. 14)

A. By whom

a. school authorities

b. police

c. stranger

d. other (specify)

B. How were you caught?

a. in the act

b. friends finked

c. other (specify)

c. What did they do to you?

a. jailed

b. school suspension

c. threatened

d. nothing

e. other (specify)

14. Did your parents find out? Yes No (If No go to question 15)

A. How did they find out?

a. R confessed

b. friends finked

c. other (specify)

B. What did they do to you?

a. grounded

b. hit me

c. threatened

d. nothing

e. other (specify) 
15. If the opportunity came along would you take something not belonging to you again.

a. yes

b. maybe

c. don't know

d. no 
Incident \# 8

Property destruction- intended to cause substantial inconvenience to a property owner or other, person and as a result damage over $\$ 100$ worth of property; damage over $\$ 1000$ worth of property or accomplished damage by means of an explosive.

1. How often did you do this?

a. once per week or more

b. once per month

c. 2 or 3 times per month

d. once or twice every four months

e. once or twice per year

f. not at al1

2. What did you destroy?

Specify

3. What money value would you place on the damage?

a. less than $\$ 5.00$ or not known

b. $\$ 5.00$ to $\$ 100.00$

c. $\$ 100.00$ to $\$ 1,000.00$

d. over $\$ 1,000.00$

4. Did you use an explosive or fire in this destruction?

a. yes

b. no

5. Where did this happen?

a. in your neighborhood

b. outside your neighborhood but within the city

c. outside city

d. outside state

6. Were you with anyone? Yes No

\section{(if Yes)}

A. Who were they?

a. friend

b. relative

c. acquaintance.

d. stranger

e. other (specify) 
7. What were your reasons for doing this?

a. anger

b. for excitement

c. family hassles

d. other (specify)

8. Was this planned? Yes No

(if Yes)

A. How long in advance?

a. less than 5 minutes

b. 5 minutes to one-half-hour

c. one-half hour to several hours

d. longer than several hours

9. Whose idea was it to do this?

a. respondent's

b. everyone's agreement

c. someone else's

d. other (specify)

10. When did this happen?

$\begin{array}{ll}\text { a. } & \text { year } \\ \text { b. } & \text { month } \\ \text { c. } & \text { day } \\ \text { d. hour (specify) }\end{array}$ AM PM

11. Did you tell anyone about it later? Yes No

(if Yes)

A. How many people did you tell?

a. adults

b. peers

B. What relationship are these people to you?

a. parent or guardian

b. teachers

c. brother or sister

d. friend (s)

e. stranger (s)

f. other (specify)

$M F$

M F

$M \quad F$

M F

M F

M F

12. Did anyone catch you? Yes________ (If No go to question 13)

(if Yes)

A. How were you caught? 
a. law enforcement authorities on patrol

b. stranger (passerby) reported incident

c. alarm went off

d. turned self in

e. member of group confessed

f. victim told

g. other (specify)

B. What happened after you were caught?

a. court involvement

b. school discipline (specify)

c. other (specify)

13. Did your parents find out about it? Yes

No

Don't know

(if Yes)

A. How did your parents find out?

a. from neighbors

b. teachers

c. police

d. I told them

e. other (specify)

B. What did your parents do or say?

a. yelled at me

b. placed me on restriction

c. gave me a caim warning not to do it again

d. physically punished me

e. nothing

f. other (specify) 
Incident \# 9

Forcible rape- had sexual intercourse with a female 15 years or younger, or with a female that either was mentally incapacitated or physically helpless, or with a half-blooded sister, or a daugher.

1. About how often have you done this?

a. once a week or more

b. once a month

c. two or three times a month

d. once or twice every four months

e. once or twice a year

f. once

2. Where did this take place?

a. at your home

b. at someone else's home or residence

c. in an automobile or other motorized vehicle

d. in a park or similar recreational area

e. hotel or motel

f. other (specify)

3. What relationship did you have with your partner?

a. date

b. steady

c. relative

d. pick-up

e. other (specify)

4. Whose idea was it to do this?

a. respondent's

b. everyone's agreement

c. other (specify-force may have been used)

5. Were you practicing contraception of any kind?

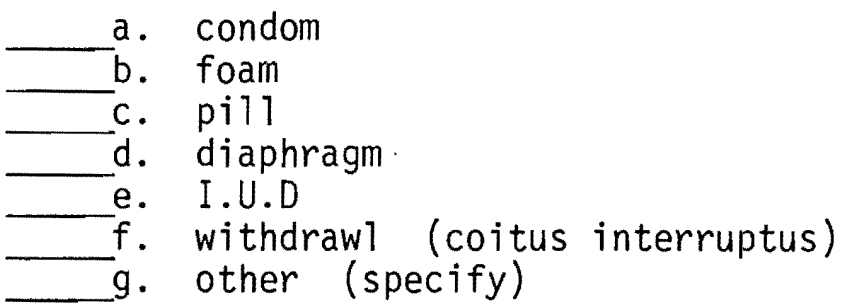


6. Was this activity planned? Yes_No____ (If No go to question 7) (if Yes)

A. How long in advance?

a. less than 5 minutes

b. 5 minutes to one-half hour

c. longer than one-half hour

d. other (specify)

7. For what reason or reasons did you do what you did?

a. excitement

b. money

c. reputation

d. curiosity

e. other (specify)

8. When did this happen?

\section{a. year}

b. month

c. day

d. hour (specify) AM PM

9. Did you tell anyone about it later? Yes No (If No go to question 10) (if Yes)

A. How many people did you te11?

a. adults

b. peers

B. What relationship are these people to you?

a. parents

b. teachers

c. brother or sister

d. friend (s)

e. stranger (s)

f. other (specify)

$\begin{array}{ll}M & F \\ M & F \\ M & F \\ M & F \\ M & F \\ M & F\end{array}$

10. Did anyone catch you or turn you in? Yes No (If No go to question 13 ) (if Yes)

A. Who caught you or turned you in?

a. friend

b. relative

c. partner told

d. teacher

e. neighbor

f. law enforcement officer

g. stranger

h. other (specify) 
11. How were you caught?

a. in the act

b. other (specify)

12. What happened after you were caught?

a. calmly discussed the matter

b. got a warning

c. placed on restriction

d. got beaten up or hit

e. got yelled at

f. sent to court

g. nothing

h. other (specify)

13. Did your parents find out about it? Yes No Don't know

(if Yes)

A. How did they find out?

a. from partner

b. from neighbors

c. from partner's parents

d. teachers

e. respondent

f. other (specify)

B. What did your parents do or say?

a. yelled at me

b. placed me on restriciton

c. given a calm warning not to do it again

d. physically punished me

e. nothing

f. other (specify) 
Incident \# 10

Sale of 111 icit drugs- knowlingly transfer or exchange drugs for money or other valuable goods or services.

1. How often have you engaged in selling drugs?

a. once per week or more

b. once per month

c. 2 or 3 times per month

d. once or twice every four months

e. once or twice a year

f. other (specify)

2. How long have you been dealing drugs?

a. 0-1 month

b. 2-6 months

c. 7-11 months

d. more than one year (specify)

3. Do you sell to make a profit? Yes_N_ No___ (If No go to quesiion 4) (if Yes)

- A. How much of a profiti: could you expect to make in a given week?

a. less than $\$ 5: 00$

b. between $\$ 5-\$ 10$

c. between $\$ 11-\$ 25$

d. more than $\$ 26$ (specify)

4. What have you sold?

a. uppers (amphetamines)

b. downers (tranquilizers)

c. hallucinogens (LSD, THC, mescaline, peyote)

d. opiates (heroine, morphine, etc.)

e. cocaine

f. other (specify)

5. What are your reasons for dealing?

a. to obtain good personal stash of drugs

b. to make or keep friends

c. to make money

d. for excitement

e. other (specify) 
6. Where do the transactions usually occur?

a. home
b. friend's home
c. local hang-out
d. in car
e. school
f. other (specify)

7. Do you change, your meeting places̀?

a. yes

b. no

8. Have you ever been caught selling drugs? Yes No (If No go to question

(if Yes)

A. Who caught you?

a. friend

b. relative

c. teacher

d. neighbor

e. law enforcement official

f. stranger

g. other (specify)

9. (If caught) What resulted from your being caught?

a. diverted from the juvenile justice system to youth service center

b. time in JDH

c. counseling with CSD worker (individual, group, family)

d. reprimand

e. parental warning or restriction

f. physical punishment

g. nothing

h. other (specify)

10. Do other people know that you dea1? Yes No

(if Yes)

a. adults (numbers)

b. peers (numbers)

A. What relationship are these people to you?

a. parents or guardians

b. teachers

c. brother or sister

$M F$

M F

M F 
d. friend (s)

e. stranger (s)

f. other (specify)

$\begin{array}{ll}M & F \\ M & F \\ M & F\end{array}$

11. Did your parents find out about it? Yes

No

A. How did they find out?

a. $R$ confessed

b. friends told

c. reported by law enforcement authorities

d. reported by school authorities

e. other (specify)

B. What did they do to you?

a. grounded

b. hit me

c. threatened

d. nothing

e. other (specify) 
Incident \# 11

Possession of Illicit Drugs: Have on one's person or within one's control any drug prohibited by statute or for which a person could be legally punished for having.

1. Have you ever kept a quantity of i1licit drugs for yourself or someone else? Yes No (terminate)

2. For how long did you keep these drugs?

a. less than one day

b. one day

c. one day to one week

d. more than one week (specify)

3. How many times have you been in possession of these drugs?

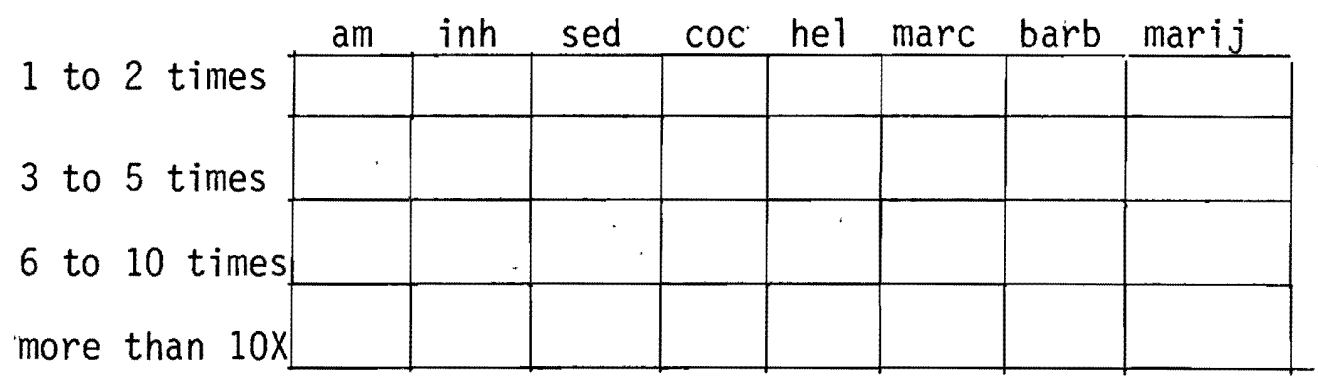

4. Where did you keep these drugs?

a. in a school locker

b. in your home or apartment

c. in a car or other motor vehicle

d. on your person

e. other (specify)

5. What are your reasons for keeping these drugs for yourself or someone else?

a. as a source of income

b. to obtain drugs for free

c. to make or keep friends or meet new people

d. for excitement

e. other (specify) 
6. Have you ever told other people about being in possession of illicit drugs? Yes No (If No go to question 7)

(if Yes)

A. Who have you told?

a. friends (s)

b. parent (s)

c. relative (s)

d. stranger (s)

e. other (specify)

$\begin{array}{ll}M & F \\ M & F \\ M & F \\ M & F \\ M & F\end{array}$

B. How many people have you told? (number)

a. peers

b. adults

7. Have you ever been caught in possession of illicit drugs? (not selling or use but possession) Yes No (terminate)

(if Yes)

A. Who caught you?

a. friend

b. relative

c. teacher

d. neighbor

e. law enforcement official

f. stranger

g. other (specify)

8. What resulted from your being caught?

a. "diverted" from juvenile justice system into a youth service center.

b. spent time in juvenile detention facility

c. official reprimand

d. parental warning or restriction

e. parental physical punishment

f. nothing

g. referred to CSD or other public or private counseling center

h. other (specify)

9. (If court involvement)

Did involvement with the juvenile court stop you from engaging in similar behavior again? Yes No

10. Did your parents find out about your getting caught? Yes No
A. How did they find out? 
a. R confessed

b. friends told

c. reported by law enforcement authorities

d. reported by school authorities

e. other (specify)

B. What did they do to you?

a. grounded

b. physical punishment

c. reprimand

d. nothing

e. other 


\section{Incident \# 12}

Use of Illicit Drugs- Knowingly use or be under the influence of any narcotic or dangerous drug unless it was dispensed or administered by a person authorized by law to do so.

1. What kinds of the following drugs have you usee? (Show colored cards to help person indentify if necessary.)

a. amphetamines (diet pills, benzedrine, dexadrine, speed, whites)

b. inhalants (glue, gasoline, nail polish remover, lighter fluid, ether,paint thinner, rubbing alcohol, etc.)

c. sedatives and tranquilizers (Chloral hydrate, compoz, stellazine, vistaril, miltown equanil, valium, librium, thorazine, mellaril doridan,etc.)

d. cocaine (coke, flacke, gold dust, snow, stardust, etc.)

e. hallucinogens (LSD, DMT, acid, n3tmeg, STP, peyote, morning glory seeds, etc.)

f. narcotics (codeine, morphine, heroin, opium, crystal, demerol, fix, horse, sugar, etc.

g. barbituates (phenobarbitol, barbs, amytal, goofballs, reds, blues, pinks, nembutal, seconal, yellow jackets, dolls, etc.)

h. marijuana (pot, weed, grass, maryjane)

2. "How may times have you used these drugs?

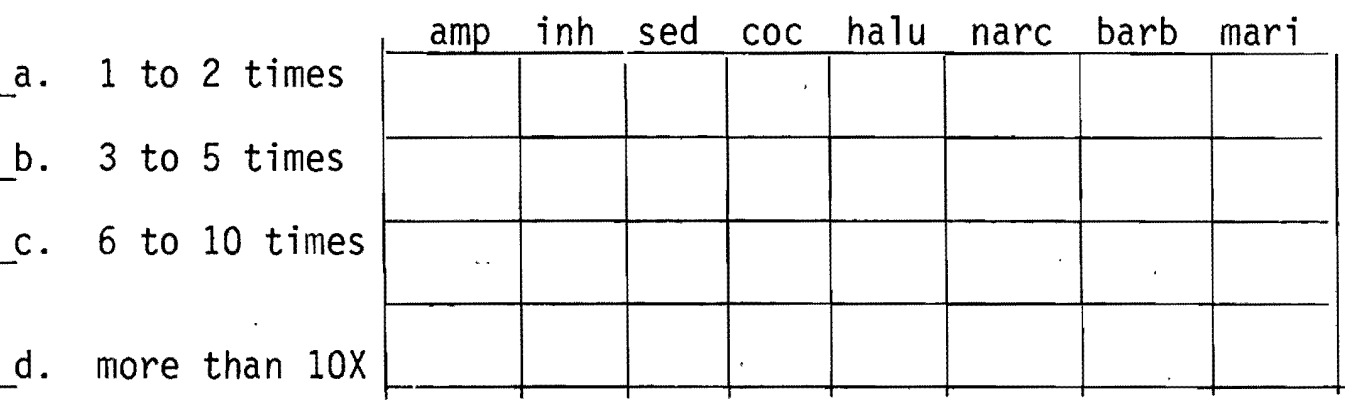

3. Whose idea was it to use these drugs:

a. respondents

b. other persons

c. everyones' agreement

d. other (specify)

4. Have you ever told others about your use of drugs?

Yes___ No___ (If No go to question 5) 
A. Who have you told?

a. friend

b. parent

c. relative

d. stranger

e. other (specify)

\section{$M \quad F$}

M F

M F

M F

B. How many peoply have you told? (number)

a. peers

b. adults

5. Where do you go to use drugs?

a. home

b. friends' home

c. school

d. car or other motorized vehicle

e. local hang-out

f. other (specify)

6. From who do you get drugs?

a. school friend (s)

b. outside of school friend (s)

c. stranger

d. someone who sells drugs for a living

e. other (specify)

7. What are your reasons for using drugs? (A sense of timing and rapport important here. Help person tell you.)

a. anger

b. excitement

c. relaxation

d. curiosity

e. because friends use them

f. feel less like a "freak", less lonely

g. to feel happy

h. other (specify)

8. When do you usually use drugs?

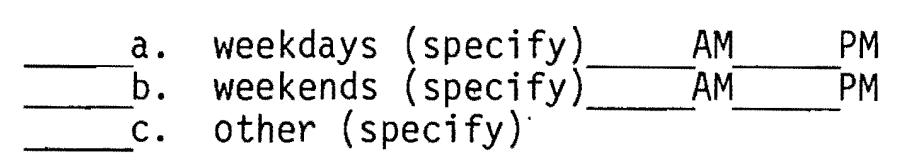

9. Have you ever been caught?

Yes__ No___ (If No go to question 10) 
A. Who caught you?

a. school authorities

b. police

c. stranger

d. family member

e. other (specify)

B. What resulted?

a. court action

b. threatened with punishment

c. nothing

d. other (specify)

e. diverted from court, sent to Youth Service Center

10. Did your parents find out?

Yes_No_ Don't know___ (If No go to question 11)

A. How did they find out?

a. R told them

b. friends told

c. authorities told

d. other (specify)

B. What did parents do?

a. grounded me

b. hit me

c. threatened

d. nothing

e. other (specify)

11. Have you ever physically injured yourself or suffered uncomfortable physical sensations after you took a drug?

Yes No

(If Yes)

A. What drug (s) did you take? (List them)

B. Describe the injury or physical sensations. 
APPENDIX B

COLORED PICTURES OF THREE DIFFERENT

TYPES OF DRUGS 
DOCTORS SOMETIMES PRESCRIBE THESE FOR LOSING WEIGHT. PEOPLE ALSO USE THESE ON THEIR OWN TO MAKE THEM FEEL MORE WIDE-AWAKE, PEPPY OR ALERT. THE PILLS ON THIS CARD ARE SOMETIMES CALLED "UPS" OR "UPPERS," "SPEED" OR "BENNIES."
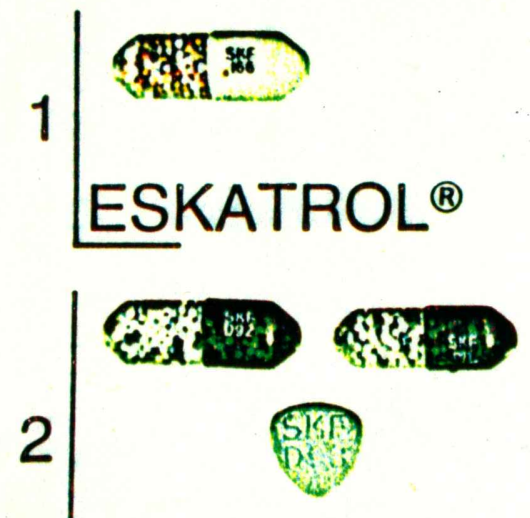

DEXAMYL ${ }^{\circledR}$

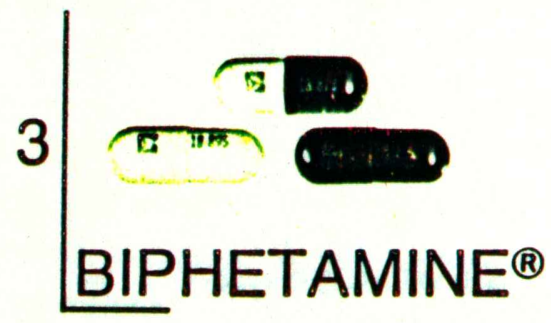

4 ब

DEXEDRINE ${ }^{\circledR}$

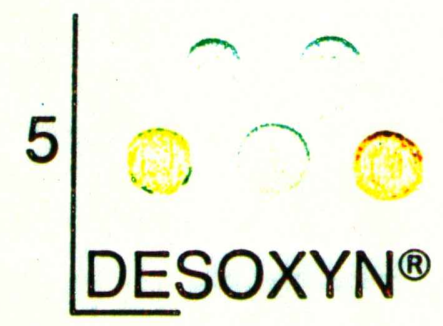

6 DESBUTAL ${ }^{\circledR}$

7 OBEDRIN ${ }^{\circledR}$

8 METHEDRINE
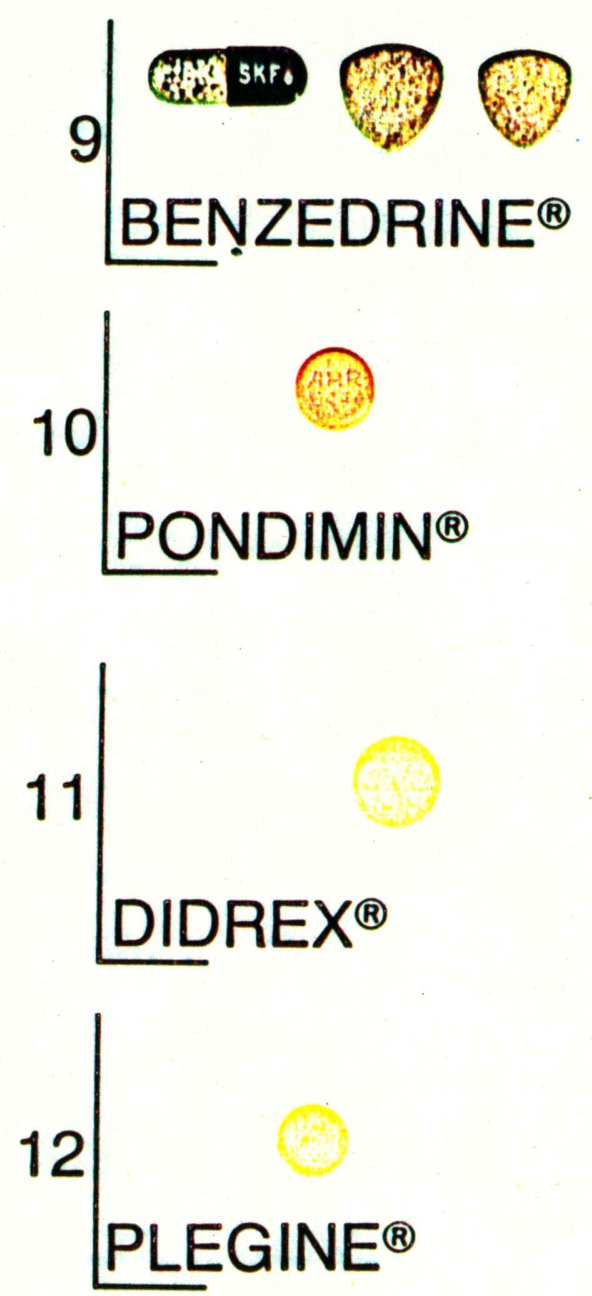

13 BAMADEX ${ }^{\circledR}$

14 AMBAR $^{\circledR}$

15 BIPHETAMINE-T ${ }^{\circledR}$

16 DEXTROAMPHETAMINE

17 MERATRAN ${ }^{\circledR}$
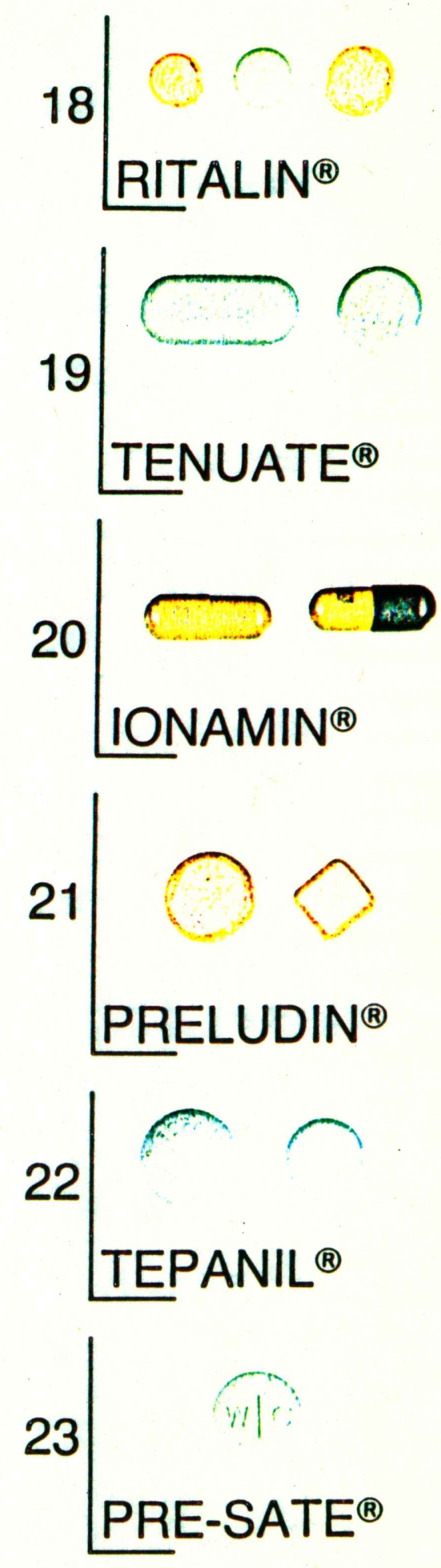
$\operatorname{rad} \beta 12$

DOCTORS SOMETIMES PRESCRIBE THESE TO HELP RELAX DURING THE DAY AND TO GET A BETTER NIGHT'S SLEEP. PEOPLE ALSO USE THESE ON THEIR OWN, TO HELP RELAX AND JUST TO FEEL GOOD. THESE ARE BARBITURATES OR SEDATIVES AND ARE SOMETIMES CALLED "DOWNS" OR "DOWNERS."

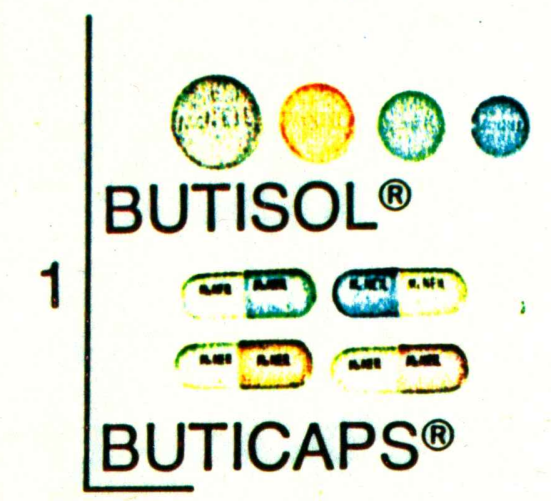

2 CARBRITAL

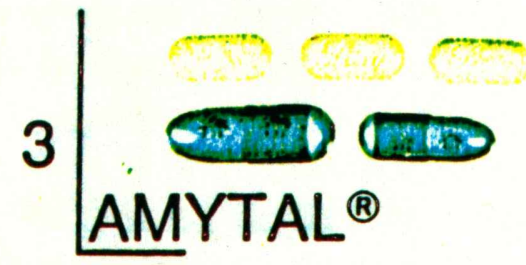

$4 \underset{\text { PLEXONAL }^{\circledR}}{\nabla}$

$5 \mid \begin{aligned} & \text { ESKABARB } \\ & \text { ESKA }\end{aligned}$

6 ALURATE $^{\circledR}$

7 PHENOBARBITAL 8 AMOBARBITAL
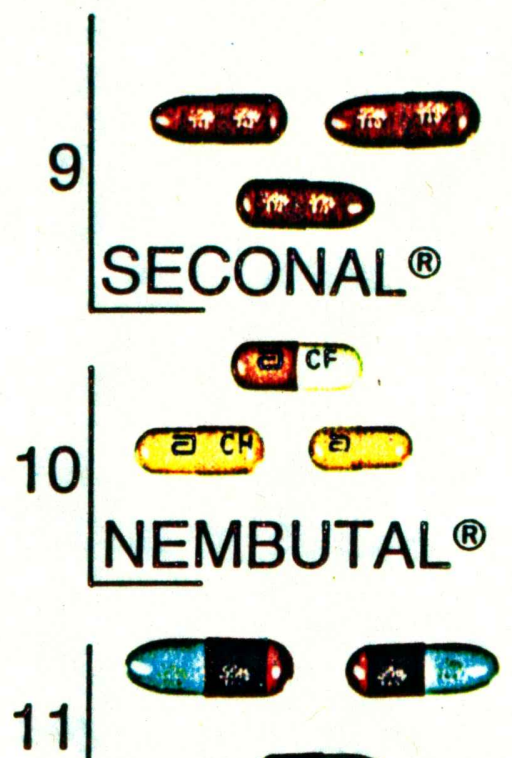

\section{$\rightarrow$}

TUINAL ${ }^{\circledR}$

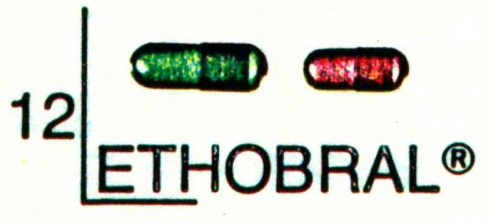

$\left.13\right|_{\text {DALMANE }}{ }^{\circledR}$

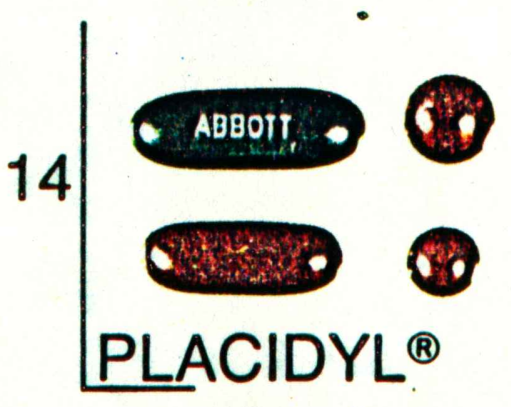

15 PENTOBARBITAL 16 SECOBARBITAL
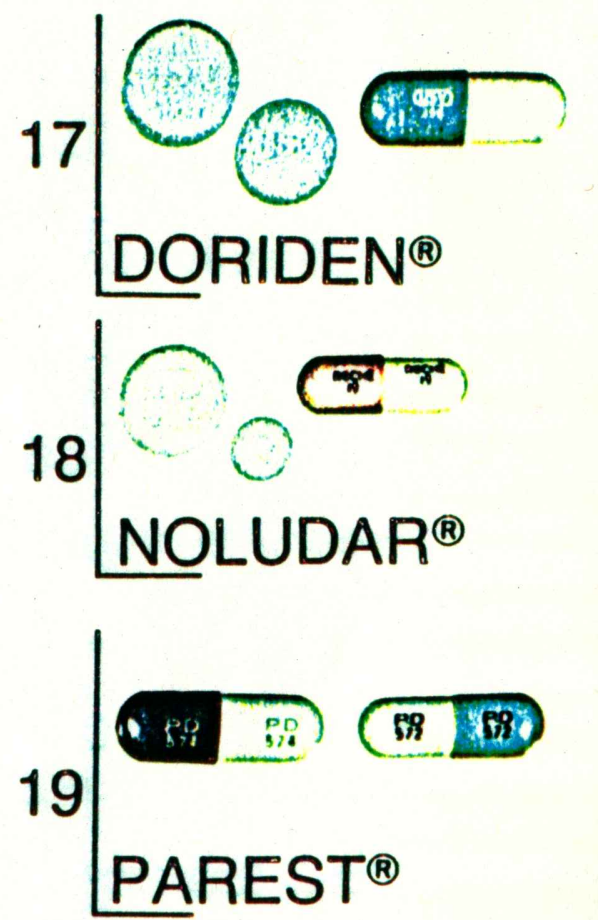

20
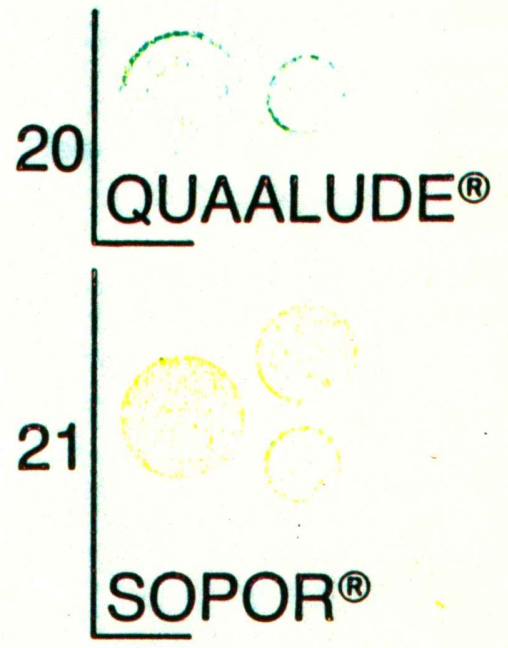

22 METHAQUALONE 
DOCTORS SOMETIMES PRESCRIBE THESE TO CALM PEOPLE DOWN OR QUIET THEIR NERVES, OR RELAX THEIR MUSCLES. PEOPLE ALSO TAKE THEM ON THEIR OWN TO MAKE THEM FEEL BETTER. THESE ARE TRANQUILIZERS.
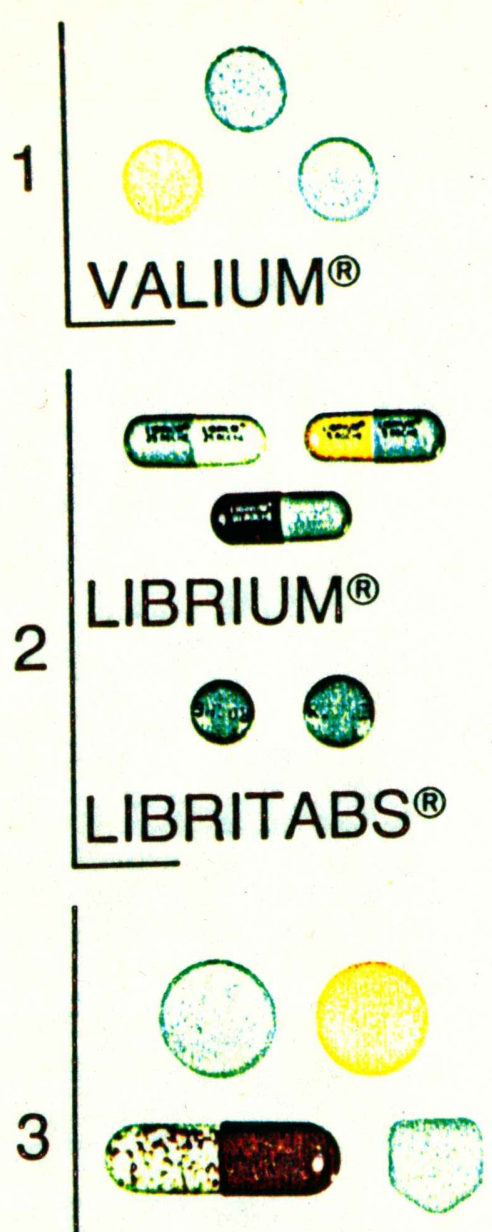

EQUANIL ${ }^{\circledR}$
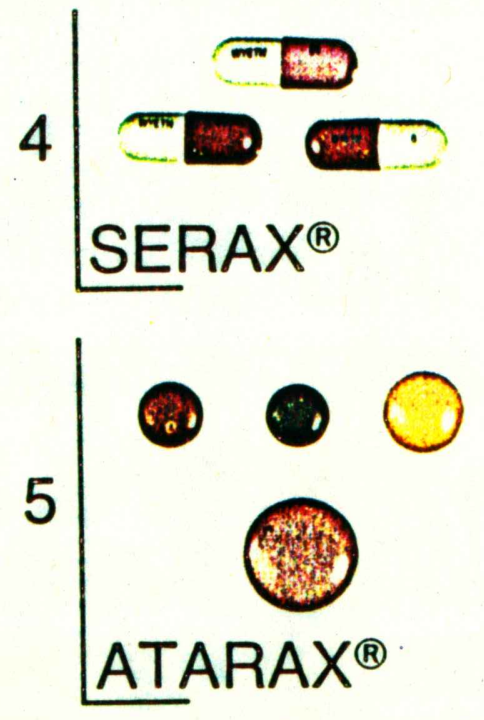
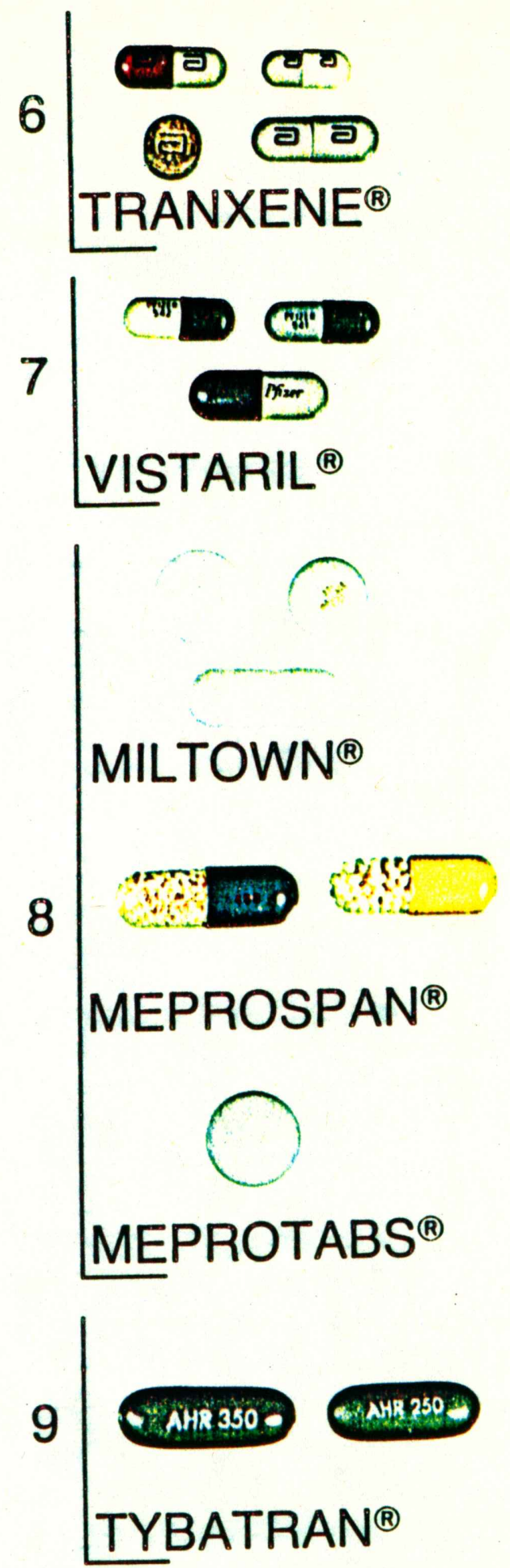

10 MEPROBAMATE 
APPENDIX C

HOLLINGSHEAD'S TWO FACTOR INDEX SOCIAL POSITION 
Below are the occupation and education scales used in Hollingshead's Two-Factor Index of Social Position, from a Decade Later: A Followup of Social Class and Mental I1lness by Myers and Bean.

The occupation scale ranks professions into different groups and businesses according to their size and value. The seven positions on the scale are:

1). executives: and proprietors of large concerns and major professionals;

2). managers and proprietors of medium concerns and minor professionals;

3). administrative personnel of large concerns (managers), owners: of small businesses and semi-professionals;

4). owners of little businesses, clerical and sales workers and technicians;

5). skilled workers;

6). semi-skilled workers;

7). unskilled workers;

This scale is based upon the assumption that different occupations are valued differently by menbers of society. The hierarchy ranges from the Tow evaluation of unskilled physical labor toward the more prestigeful use of skill such as creative talents, ideas and management of men. (Myers and Bean, p. 235)

The seven positions on the Educational scale are:

1). graduate professional training (persons who completed a recognizable course which led to the receipt of a graduate degree);

2). standard college or university graduation (individuals who completed a four-year college or university course leading to a recognized college degree); 
3). partial college training (individuals who had completed at least 1 year but not a full college course);

4). high school graduation (a11 secondary-school graduates, whether from a private prepatory school, public high school, trade school or a parochial high school);

5). partial high school (individuals who had completed 10th or 11th grades but not the high school course);

6). junior high school (individuals who completed 7, 8, 9th grades);

7). less that 7 years of school (individuals who had completed less than 7 grades irrespective of the amount of education received);

The educational scale is based upon the assumption that men and women who possess similar educations tend to have similar tastes, attitudes and to exhibit similar behavior patterns. (Myers and Bean 1968, p. 236)

To calculate an Index of Social Position or SES for an individual, the scale value for occupation, the number assigned to the position of the scale 1 through 7 , is multiplied by the factor weight for occupation, or 7 . The scale value for education, 1 through 7 , is multiplied by the factor weight for education or 4 . The two scores are added together for an index score. The possible scores range from 11 to 77 , with 11 representing the highest position an individual can reach in terms of education and occupation. A score of 77 would be assigned to an individual with less than 7 years of schooling who was an unskilled laborer.

Below is an example of how the highest score would be computed:

Factor Scale Score Factor Weight Score $x$ Weight

Occuaption

Education

Index Score

\section{1}

1

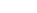

\section{7}

4

$-$
7

4

11 


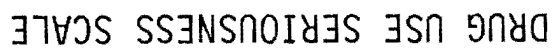

\author{
0 XIONGdd
}


DRUG USE* SERIOUSNSS SCALE

\begin{tabular}{|c|c|}
\hline $\begin{array}{l}\text { Degree of } \\
\text { Seriousness }\end{array}$ & $\begin{array}{l}\text { SELF-TARGET } \\
\text { Drug use resulting in: } \\
\end{array}$ \\
\hline 4 & $\begin{array}{l}\text { LOSS OF CONSCIOUSNESS (NON-SLEEP), AMENSIA } \\
\text { ATTEMPTED SUICIDE OR ACCIDENT RESULTING IN } \\
\text { EXTENDED HOSPITALIZATION }\end{array}$ \\
\hline 3 & $\begin{array}{l}\text { SELF-INFLICTED ABUSIVE ACTS RESULTING IN NECESSARY } \\
\text { MEDICAL TREATMENT SUCH AS: BROKEN BONES, BURNS, } \\
\text { SEVERE PUNCTURES OR BRUISES, CUTS }\end{array}$ \\
\hline 2 & $\begin{array}{l}\text { MINOR BODILY INJURIES SUCH AS BRUISES AND CUTS } \\
\text { THAT REQUIRE SELF-ADMINISTERED MEDICAL TREATMENT }\end{array}$ \\
\hline 1 & $\begin{array}{l}\text { MINOR DISORIENTATION, SLIGHT DIFFICULTY IN WALKING, } \\
\text { SLURRING OF SPEECH, BLURRING OF VISION, MILD HANGOVER } \\
\text { CHARACTERIZED BY THROBBING HEAD AND NAUSEA }\end{array}$ \\
\hline & $\begin{array}{l}\text { *Drug use defined as consumption, in any manner of illicit } \\
\text { drugs }\end{array}$ \\
\hline
\end{tabular}


SINJONIS

ONH

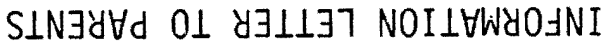

$\exists \quad X I O N \exists d d \forall$ 


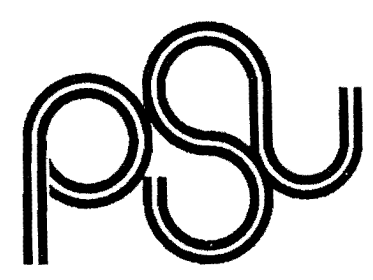

November 15,1976

Dear Student and Parent:

We are a group of graduate students fulfilling our research requirement for our Masters of Social Work degree. The four of us are concerned with adolescent's spare time activities. Your names were chosen by a scientific selection process to be representative of youth in this area. All responses made by the student will be held in strictest confidence with numbers used instead of names.

It is our hope that the information we obtain will benefit educators, community programs and youth service agencies. Our findings may also affect changes in curriculum and course offerings which could benefit your child's educational experience.

We will be contacting the student to arrange for an interview at a convenient time. Thank you very much for your cooporation.

Sincerely,

Portland State University Thesis Committee 
$\perp N \exists W \exists \perp \forall \perp S \quad 7 \forall Y \cap 0 \exists J 0 y d$

$\exists X I O N \exists d d Y$ 
Procedural statement for a research project

to examine:

DELINQUENT BEHAVIOR AMONG

HIGH-SCHOOL STUDENTS

IN PORTLAND, OREGON

1976

\author{
Stan Hahn \\ Judy Casey \\ Susan Goldsmith \\ Mario Bolivar \\ PSU School of Social Work \\ John Longres Ph.d.- Advisor
}


In order to fulfill the research requirement for the Master of Social Work degree, a comprehensive examination fo a particular subject area is necessary. Our particular research interests at this time concern the incidence and distribution of delinquent behavior among high school age adolescnets. Delinquent behavior refers to offensive behavior of juveniles whether or not it is ever detected by authorities or anyone else. It is not juvenile delinquency, which concerns the nature and background of youthful offenders apprehended by the police and declared delinquent by a court of law. Juvenile delinquency concerns the interactive behavior of juveniles, their parents, policemen, court workers, judges, and others. Delinquent behavior is another matter. Brief reflection will confirm that it constitutes the bulk of the social problem of delinquency.

It is hoped that this proposed research would identify delinquent benavior through frank and intensive questionning of a representative sample of high school students at Adams. The self-report technique, utilizing an interview rather than a questionnaire would be utilized.

\section{Procedure}

Each randomly selected youngster and his parent or guardian would be informed by mail or telephone of this Portland State University Youth Study Project of teen-agers' spare-time activities. Mention of the confidentiality of this study would be stressed early on. No names would be necessary, each student being assigned a number. The data obtained would only be used in group or collective form, not individually. An attempt to interview the student during free time, lunch, or other convenient 
time would be made.

An introductory statement, read to the student before the interview could proceed as follows:

Several social science researchers at the Portland State University School of Social Work are interested in finding out more about what teenagers do in their daily lives and how they feel about things. We would like to discover how things look from the point of view of people your age.

We want to reassure you at this time that your participation in this study will remain strictly confidential. The nature of some of the questions asked of you will deal with very sensitive subject matter. We want to say that your identity will be completely anonymous. Your name will be thrown out and your interview will be assigned a number.

We believe that there is a whole part of teenagers' lives which we know very little about. That is the part about things teenagers do which are against the rules, or even against the law, and which they don't want adults to find out about. For example, we know very little about how many people break rules at school and are never caught. For another example, we know very little about people who break one kind of law or another, very few of whom are caught by the police.

We know that many kids do things that could get them into trouble if they were caught. In order for us to really understand teenagers, it has been necessary for us to talk with kids who have done things which might have gotten them into trouble, but who have never been caught. This is just what fellows and girls have been telling us about in this study. Now in order to be sure we are asking teenagers who represent all the teenagers around here, we picked the names of 160 kids scientifically on a chance basis. We know that from other studies, if we select a small gorup of people scientifically, we can be pretty certain that they will give us the same kind of answers, on the average, that we would get if we interviewed all the people. Of course, we can't afford to interview al1 teenagers, so we have picked 160 instead. It's like a cook tasting a por of soup. He can tell from one little sip how the whole pot will taste. He doesn't have to drink the whole pot of soup. We11, this is the same thing. We can tell, from talking with 160 kids, how teenagers in general feel about things and what they do. Each one of the names we have picked scientigicallu to be one representative of all teenagers atound here. Your name was one of those picked. However, while your answers are very important, it is even more important that we interview you only if you are willing to be very honest in your answers.

As I said, some of the questions will be about things which might have gotten you into trouble if the police or your parents had found out about them. You do not have to worry about our telling anyone what you say. I can guarantee that no one, outside of the study staff will see you answers. In fact, your interview sheet will get a number. Neitlier 
your name nor anything else which might identify you will ever be put on this interview. Your answers will be coded in our office at Portland State University with just a number on them.

How do you feel about it? Are you willing to cooperate with us on this study? Will you answer some questions about rules you might have broken at home, or in school, or around town? Take some time to think about it before answering--your honesty in answering our questions is necessary.

\section{The Interview}

The primary dependent variable in this study is delinquent behavior. It will be measured well on into the interview, after questions. about family, friends, school and perhaps one or two other areas are discussed. Respondents will ve presented with a packet of (possibiy prepundhed) cards on which are printed brief descriptions of delinquent acts. (See Chart I for the list of items and the abbreyiated titles of the acts that we will use hereafter.) They will be asked tosort items into three piles, indicating whether they had committed each act "never," "once," or "more than once" in the previous three years. They will be told that they will be asked some further questions about those offenses they had committed. Students will be reminded ot the anonymity and confidentiality of the interview and will be urged not to respond at all if they feel they cannot be completley honest and open.

Interviewers will follow up the card sort by asking questions designed to obtain full descriptions of the three most recent incidents of each of the items to which the respondents confess. A major reason for recording these details is to assess the seriousness of each act, which is one component in gauging the degree of an individual's delinquency. For example, we may find that a relatively high percentage of "offenses" 
described by respondents will later be judged to be too trivial to be considered actually delinquent.

The actual interview is different for each youngster, adapted to the offenses to which he responds to on the card sort. The interview could last anywhere from 35 minutes to $1 \frac{1}{2}$ hours, depending on the extent of the youngster's responses.

A validation study measuring the extent of condealment need not be attempted. Concealment statistics arising our of an earlier study qi1l be used. Most of the methodology used in this study is based on Martin Gold's research on delinquent behavior among youth in Flint, Michigan in 1961. This research finally appeared in book form under the title:

Deliniquent Behavior in an American City. (Belmont, California: Brooks/ Cole, 1970). 

MULTNOMAH COUNTY SCHOOL DISTRICT NO.1

PORTLAND PUBLIC SCHOOLS

PERSONNEL SERVICES

(Temporary) JOB DESCRIPTION-- SCHOOL SOCIAL WORKER

Position Summary:

School social workers work cooperatively with a school staff, students, parents and community resource personnel in those areas of student behavior which interfere with the student's learning, social, and/or emotional adjustment.

Major Duties and Responsibilities: (May include but not necessarily limited to)

1. Defines role, objectives, and procedures of the school social worker with school staff.

2. Assists teachers and/or principals in problem identification and in determining the appropriateness of referrels.

3. Develops a plan of action including the designation of responsibility

of various personnel involved in the implementation of the plan.

4. Assusts the teacher and/or school staff in understanding the behavior

of the student at school, in the home, and in the community.

5. Provides services to children individually or in groups, attempting to help them cope with personal, social and/or emotional problems which interfere with their ability to make use of the school program.

6. Refiers child and his fmaily to appropriate medical and mental health, welfare and recreational agericies.

7. Works cooperatively with Children's Services, Juvenile Court and other agencies.

8. Works to improbe family relationships when they are felt to be a significant factor in the poor adjustment or poor academic performance of child. 9. Facilitates cirmunication and a cooperative relationship between parents and the school.

10. Provides an avenue of communication between community agencies and school by interpreting the functions,policies, and procedures of agencies to the school and of school to community agencies.

11. Makes reports and keeps recores as required.

12. Initiates and coordinates staffings with school personnel, family and community agencies when indicated.

Other Duties and Responsibilities:

1. Participates in professional activities (ie. research projects, instruction of graduate social work students, staff development activities, education of social work personnel).

2. Identifies needs and facilitates resource development in school and community.

3. Accepts responsibility, when assigned, within a community council, or with other planning or coordinating groups.

4. Interprets the nature of social work services to community agencies 
or interested groups.

5. Performs other reasonably related duties as assigned.

Minimum Qual ifications:

Must hold a master's degree in social work from an accredited school of social work. Experience in a recognized child welfare agency or experience as a school social worker is desired.

Supervision:

Responsible to:

TITLE



Abelson, H., Cohen, R., Schnager, D., Ruppaport, M., "Drug Experience, Attitudes, and Related Behavior Among Adolescents and Adults; Drug Use in America: Problem in Perspective (Washington, D. C.: U. S. Government Printing Office, 1973).

Bandura, A., Adolscent Agrgression (New York: The Ronald Press, 1959.)

Berube, M., and Gittel, M., Confrontation at Ocean Hill-Brownsville: The New York School Strikes of 1968. (New York: Frederick A. Phaeger, 1969).

Blue, J., "The Relationship of Juvenile Delinquency, Race and Economic Status" Journal of Negro Education, 17 (1948) pp.469-477.

Blum, R. H., Students and Drugs (San Francisco: Jossey Bass, 1969).

Brager, G. "Influencing Institutional Change Through a Demonstration Project: The Case of the Schools," in Kramer and Specht, Reading in Community Organization Practice (Englewood Cliffs, $\mathrm{N} \mathrm{J}$ : Prentice-Ha11, 1969) pp.450-458

Bruning, J. and Kintz, B., Computational Handbook of Statistics (New York: Scott, Fresman and Co., 1968)

Carman, Diane et. a1., "Handling School Drug Abuse Problem" The Oregon Journal Feb.5, 1977, pp.2-3

Chein, I. The Road to H: Narcotics, Delinquency and Social Policy (New York: Basic Books, 1964).

Clark, J. and Wenniger, E., "Socio-Economic Class and Area as Correlates of Illegal Behavior Among Juveniles". American Sociological Review 27 (1962) pp.826-834

Cloward, R. and Ohlin, L. Delinquency and Opportunity: A Theory of Delinquent Gangs (New York: Free Press, 1960).

Cohen, A., Delinquent Boys, (Glencoe Illinois: The Free Press, 1955)

Colton, L., "How I Learned Good At Vol. 3, No. 1 (Nov. 15, 1976)p. $\overline{10}$ High School," Willamette Week

Dornbusch, S. and Schmid, C., A Primer of Social Statistic. (New York: Macgraw-Hill Book Co., 1955)

Duncan, J., "Life or Death For (Nov. 15, 1976) p.1. "Willamette Week Vol.3, No.1. .

Empey, M. and Erickson, M. "Hidden Delinquency and Social Status", Social Forces 44 (June 1966) pp.546-554. 
Erickson, M. and Empey, L. "Court Records, Undetected Delinguency" Journal of Criminal Law, Criminology and Political Science, 54 (1963) pp. 456-461.

Erickson, M. and Empey, L., "Class Position, Peers, and Delinquency," Sociology and Social Research, 47 (1965 pp.268-282.

Erikson, K., "Notes on the Sociology of Deviance" Social Problems, 9 (Spring 1962) pp.308-317.

Frease, D., "Delinquency, Social Class, and the Schools," Sociology and Social Research, 57 (1973) pp.443-459.

Freidenberg, E., "The Cradce of Liberty," In Richard Flacks, Ed. Conformity, Resistance and Self Determination: The Individual and Authority (Boston: Little, Brown and Co., 1973).

Froland, Charles, Substance Abuse in Oregon: Identifying Potential Clientele, Problem Trends and Service Related Needs (Salem: Mental Health Division, 1976).

Garfinke1, H., "Conditions of Successful Degradation Cermonies," American Journal of Sociology, 61 (March 1956) pp.421-424.

Gibbons, D., Delinquent Behavior (Englewood Cliffs, New Jersey: PrenticeHa11, 1970).

Goffman, E., "On Cooling The Mark Out," Psychiatry Vol: 15, No.4. (Nov. 1952) pp.541-463.

Goffman, E., Stigma: Notes on the Management of Spoiled Identity, (Englewood Cliffs, New Jersey: Prentice-Hall, Inc. 1963)

Gold, M. "Changing Patterns in Delinquency: 1967-1972," Crime and Delinquency Literature Vol. No. (Dec. 1975) pp.

Gold, M. "On Social Status and Delinquency" Social Problems, Vol 15 pp.114-116.

Gold, M. Delinquent Behavior in an American City (Belmont, Calif. : Brooks, Cole, 1970)

Gold, M. and Haney, B. "The Juvenile Delinquent Nobody Knows, "Psychology Today, Vol. No. (Sept. 1973) pp.49-55

Gould, L. "Who Defines Delinquency: A Comparison of Self-Reported and Officially Reported" Social Problems, Vol. 16 pp.325-335.

Guinn, R and Harley, R. "A Comparison of Drug Use Among Houston and Lower Rio Grande Valley Secondary Students" Adolescence 11, Vol.42 (Fal1 197.6) pp.455-59. 
Hardt, R. and Peterson, S. "Neighvorhood Status and Delinquency Activity as Indexed by Police Records and a Self-Report Survey," Criminological 6, (May 1968) pp.37-47.

Johnson, K. :Survey of Adolescent Drug Use I," American Journal of Public Health, 61, No. 12 (Dec, 1971) pp.2418-2432.

Johnson, K. "Survey of Adolescent Drug Use II \& III, American Journal of Public Health, 62, No. 2, (Feb. 1972) pp.164-170.

Kellam, Sheppard et. a1. "Mental Health and Going to School: The Woodlawn Program of Assesment, Early Intervention and Evaluation: University of Chicago Press: Chicago, 1975.

Kelly, Delos. "Track Position and Delinquent Involvement: A Preliminary Analysis" Sociology and Social Research Vol. 58 pp.380-386

Knowels, L. and Pruitt, K. "Institutional Racism in America "Englewood Cliffs, N J: Prentice-Hall, Inc. 1969

Langely, M. and Drone, H.:Juvenile Justice Reneging on Sociological Obligation", Social Service Review, Vol. 47 (Dec. 1973) pp.

Lerman, P. "Evaluative Studies of Institutions for Delinquents". Social Work Vo1. 13, (JuTy 1968) pp.55-64

Liska", Allen, "Casual Structures Underlying the Relationships between Del inquent Involvement and Delinquent Peers." Sociology and Social Research Vol. 58 pp.23-26

Matheson, Douglas et. a1. "Introduction to Experimental Psychology" Holt Rinehart and Winston Inc.: New York, 1974

Matz, David "Delinquency and Drift" New York: John Wiley and Sons, Inc., 1964.

Maziotti, Katie, "Portland's High: From Free School to Re-School." Willamette Week Vol. 2 No. 18 (Mar. 15,1976) pp. 8.

Multnomah County, Oregon Juvenile Court Annual Reports 1971-1975

Myers, J. and Bean,.L. "A Decade Later: A Follow Up of Social Class and Mental Illness: New York: Wiley Pub., 1968

Nettler, Gwynn "Explainning Crime" New York: McGraw-Hi11, 1974.

Oregon, "Proposed Revision Oregon Juvenile Code" (1976), Salem: Legislative Interim Committee on Judiciary. 
Oregon Council on Crime and Delinquency"A Lossing Battle: An Analysis of Counseling Services in Oregon's Juvenile Courts," (Prepared in Support of House Bi11 1038, March 1967.)

Pincus, Allen and Minahan, Anne, "Social Work Practice: Model and Method" Itaska, I11.: F E Peacock Pub., Inc.,1973.

Pittel, S. The Etiology of Youthful Drug Involvement:, Drug Use in Ameriea: Problem in Perspective, Wash. D. D. : U. S. Govt Pringing Off., (Mar. 1973) pp. 879-913.

Piven, Frances and Cloward, Richard "The Politics of Turmoil" New York Vintage, 1974.

Polier, J. "Myths and Realities in the Search for Juvenile Justice: A Statement by the Honorable Justice Wise Polier." The Rights of Children, (Harvard Educational Review: Reprint Series No. 9) pp.109-119.

Poterfield, Austin. "Delinquency and its Outcome in Court and College". The American Journal of Sociology, Vol XLIX Nov. 1943, pp.199-208

Preisdent's Commission on Law Enforcement and Adminsitration of Justice, Task Force Report; Juvenile Del inquency and Youth Crime, (Wash. D. C. U S Gov Printing Off. 1967)

Reed, John P and Baali Fuad "Faces of Delinquency" Engelwood Cliffs, N J Prentice-Ha11, inc. $197 \overline{0}$

Reiss, A. "Occupations and Social Status" New York: Free Press, 1961

Ryan, William, "Blaming the Victim: New York: Vintage, 1971.

Schur, E. "Labelling Deviant Behavior: Its Sociological Significance" Englewood New Jersy, Prentice-Ha11, 1971.

Schur, E: "Radical Non-Intervention ReThinking the Delinquency Problems" Englewood Cliffs, New Jersey: Prentice-Ha11, 1973.

Schwartz, E. "A Community Experment in the Measurement of Juvenile Delinquency" Nat. Prob Assoc Yearbook, 1945 (Washington D. C. U. S. G.P.O., 1947)

Sellin, Thorten and Wolgang, Marvin, "The Measurement of Delinquency " New York: Wiley, 1964 
Sennett, Richard and Cobb, Jonathan, "The Hidden Injuries of Class" New York, Vintage, 1972.

Shafer, Walter and Polk, Kenneth "Delinquency and the School's in Task Force Report: Juvenile Delinquency and Youth Crime. Washington D. C. U. S. Government Printing Off. 1967, pp. 222-277

Shanley, Fred, "Middle Class Delinquency as a Social Problem" Sociology and Social Research, L 1 (Jan. 1965) pp. 185-198.

Short, James, and Nye Ivan, "Extent of Unrecorded Juvenile Delinquency

Tentative Conlusions' Journal of Criminal Law Criminology and Police Science. Vol 47, No. $58 \mathrm{pp} .296-302$

Short, James and Nye, Ivan. "Reported Behavior as a Criterion of Deviant Behavior: Social Problems, (Winter, 1958) pp.207-213.

Sjoberg, Gideon, "Ethics, Politics, and Social Research: Cambridge, Mass Schenkman Publishing Co., 1967

Tec, Nechama, "Some Aspects of High School Status and Differential Involvement with Marijuana: A Study of Suburban Teenagers," Adolescence Vol. 7, No.25 (Spring 1972) pp.1-28

Williams, Jay and Gold, Maring, "From Delinquent Behavior to Official :Delinquency," Social Problems, Vol. 20 (Fall 1972) pp. 209-229.

Witmer et. a1, "The Inidence of Hidden Del inquency American Journal of Orthopsychiatry XVI (Oct, 1946) pp. 686-695 